\title{
Applications of Dendrimers in Drug Delivery Agents, Diagnosis, Therapy, and Detection
}

\author{
B. Noriega-Luna, ${ }^{1}$ Luis A. Godínez, ${ }^{1}$ Francisco J. Rodríguez, ${ }^{1}$ \\ A. Rodríguez, ${ }^{1}$ G. Zaldívar-Lelo de Larrea, ${ }^{2}$ C. F. Sosa-Ferreyra, ${ }^{2}$ R. F. Mercado-Curiel, ${ }^{2}$ \\ J. Manríquez, ${ }^{1}$ and E. Bustos ${ }^{1}$ \\ ${ }^{1}$ Centro de Investigación y Desarrollo Tecnológico en Electroquímica S.C., Parque Tecnológico Querétaro s/n, Sanfandila, \\ 76703 Pedro Escobedo, QRO, Mexico \\ ${ }^{2}$ Medicine Faculty, Universidad Autónoma de Querétaro, Fraccionamiento Prados de la Capilla, \\ 76176 Santiago de Querétaro, QRO, Mexico
}

Correspondence should be addressed to E. Bustos; ebustos@cideteq.mx

Received 11 November 2013; Accepted 7 February 2014; Published 15 April 2014

Academic Editor: Mustafa O. Guler

Copyright (C) 2014 B. Noriega-Luna et al. This is an open access article distributed under the Creative Commons Attribution License, which permits unrestricted use, distribution, and reproduction in any medium, provided the original work is properly cited.

In recent years, the application of dendrimers in biomedicine attracted much attention from scientists. Dendrimers are interesting for biomedical applications because of their characteristics, including: a hyperbranching, well-defined globular structures, excellent structural uniformity, multivalency, variable chemical composition, and high biological compatibility. In particular, the threedimensional architecture of dendrimers can incorporate a variety of biologically active agents to form biologically active conjugates. This review of dendrimers focuses on their use as protein mimics, drug delivery agents, anticancer and antiviral therapeutics, and in biomedical diagnostic applications such as chemically modified electrodes.

\section{Introduction}

Dendrimers are a class of well-defined hyperbranched polymers first developed under the name cascade polymers by Buhleier et al. in 1978 [1]. These initially small hyperbranched molecules were the basis for polypropylene imine (PPI) dendrimers, developed by the Meijer and Mülhaupt groups in the early 1990s [2, 3]. In 1983, Tomalia et al. reported a new class of dendrimers based on a mixture of amines and amides, the so-called polyamidoamine dendrimers, commonly known as PAMAM dendrimers [4]. A number of other dendrimer designs were reported by various research groups during the 1980s and 1990s, and the development of new dendrimer designs is ongoing [5]. The word dendrimer arises from the Greek dendron, meaning "tree" or "branch," and meros meaning "part." Other names for dendrimers are "arboroles" or "cascade polymers."

On a molecular level the dendritic branching results in semiglobular to globular structures, mostly with a high density of functionalities on the surface together with a small molecular "volume." A typical dendrimer is comprised of three different topological parts: (a) a central core which is either a single atom or an atomic group having at least two identical chemical functions; (b) building blocks with several interior layers composed of repeating units; and (c) multiple peripheral functional groups, generally located on the exterior of the macromolecule, which play a key role in their properties. The first part, the focal core, encapsulates various chemical species that exhibit unparalleled properties due to the special nanoenvironment surrounded by extensive dendritic branching. Next, the various interior layers composed of repeating units provide a flexible space created within the voids of dendritic building blocks, which are able to encapsulate various small guest molecules. Finally, the third part of a dendrimer is the multivalent surface, which can accommodate a large number of functionalities which can interact with the external environment, thereby defining the dendrimer's macroscopic properties [6]. 
The three-dimensional structure of dendrimers gives them a variety of unique properties, such as nanoscaled globular shape, well-defined functional groups at the periphery, hydrophobic or hydrophilic cavities in the interior and extremely low polydispersity [7], and thus a wide range of potential applications. For example, most dendrimers have globular structures with molecular diameters less than $10 \mathrm{~nm}$, which can be modulated by varying dendrimer generations. This property gives dendrimers similar sizes and shapes as specific proteins and other biomolecules and thereby makes them perfect as biomimics [8]. Also, the highly regular branching pattern of dendrimers imbues these dendritic architectures with well-defined numbers of periphery functional groups, providing opportunities for the presence of drug molecules, targeting moieties, and solubilizing groups on the surface in a multivalent fashion [9-12]. Moreover, hydrophobic and hydrophilic cavities in the interior of dendrimers make them useful candidates as unimolecular micelles for the encapsulation of guest molecules, especially drugs [13-15]. Finally, the low polydispersity of dendrimers assures the reproducibility of biodistribution of polymeric prodrugs using them as scaffolds $[16,17]$.

During the last decade, these dendrimers have proved to be promising nanocarriers for various drugs including antiinflammatory, antimicrobial, and anticancer drugs [18-20] in different routes of drug administration [21, 22]; however, the application of dendrimers as scaffolds of prodrugs is particularly interesting [23-25]. Dendrimers are interested in the discovery of drugs by virtue of their activities against prion diseases [26], Alzheimer's disease [27], inflammation [28], HIV [29], herpes simplex virus (HSV) [30], bacteria [31], and cancer [32]. In this review, we study the applications of dendrimers as protein mimics, delivery agents for drugs, and anticancer or antiviral therapeutics. In addition, we also discuss the use of dendrimers in biomedical diagnostic applications such as modified electrodes.

\section{Dendrimers as Possible Globular Protein Mimics}

Proteins are amphiphilic molecules that use macromolecular scaffolds to control the presentation of functional groups at their surfaces. Given the versatility of proteins as functional materials in biological systems, it is desirable to understand and develop ways to control presentation of functional groups in synthetic amphiphilic macromolecules. Recently, polymeric scaffolds have been used to achieve biomimetic functions $[33,34]$. It should be noted that dendrimers are the only class of artificial macromolecules that are an excellent choice for biomimicry of proteins due to their high molecular weights and branched architecture.

In this context, within the PAMAM dendrimers family, some molecules closely match the sizes and contours of many important proteins and bioassemblies. For example, insulin $(3 \mathrm{~nm})$, cytochrome $\mathrm{C}(4 \mathrm{~nm})$, and hemoglobin $(5.5 \mathrm{~nm})$ are approximately the same size and shape as ammoniacore PAMAM dendrimers generations 3, 4 and 5, respectively (Figure 1). Furthermore, generations 5 and 6 PAMAM dendrimers have diameters approximately equivalent to the
TABLE 1: Some properties calculated to PAMAM dendrimers by generation $[4,6,8]$.

\begin{tabular}{lccc}
\hline Generation & $\begin{array}{c}\text { Molecular } \\
\text { weight }^{\mathrm{a}}\end{array}$ & Diameter $(\AA)^{\mathrm{b}}$ & $\begin{array}{c}\text { Functional } \\
\text { groups }\end{array}$ \\
\hline 0 & 517 & 15 & 4 \\
1 & 1430 & 22 & 8 \\
2 & 3256 & 29 & 16 \\
3 & 6909 & 36 & 32 \\
4 & 14215 & 45 & 64 \\
5 & 28826 & 54 & 128 \\
6 & 58048 & 67 & 256 \\
7 & 116493 & 81 & 512 \\
8 & 233383 & 97 & 1024 \\
9 & 467162 & 114 & 2048 \\
10 & 934720 & 135 & 4096 \\
\hline
\end{tabular}

${ }^{\mathrm{a}}$ The molecular weight is based on an ideal structure of the dendrimer.

${ }^{\mathrm{b}}$ Molecular dimensions were determined by size exclusion chromatography.

thickness of lipid bilayer membranes $(\sim 5.5 \mathrm{~nm})$ of biological cells, while a generation 2 dendrimer matches the width (2.4 nm) of DNA duplexes.

However, although there are many similarities between dendrimers and globular proteins, it is also important to note significant differences. Whereas globular proteins are tertiary structures resulting from the intricate folding of sequenced linear structures, they are extremely fragile and susceptible to denaturing conditions, such as temperature, light, and $\mathrm{pH}$. Furthermore, folded proteins generally produce densely packed interiors and surfaces possessing highly heterogeneous domains of functionality, hydrophobicity, and hydrophilicity. In contrast, dendrimers are robust, covalently fixed, three-dimensional structures possessing both a solvent-filled interior core (nanoscale container) and a homogenous, mathematically defined, exterior surface functionality (nanoscaffold) [35], as PAMAM dendrimers (Table 1 and Figure 2). The next sections show examples of mimetic applications of dendrimers.

2.1. Dendrimers Mimicking in Angiogenesis. The dendrimers that mimic the surface structure of proteins involved in angiogenesis inhibition have been developed for use in antitumor systems [36]. Angiogenesis is an important process for tumor growth which is initiated by angiogenic factors, such as vascular endothelial growth factor (VEGF) and basic fibroblast growth factor (b-FGF). These growth factors bind to their receptors on endothelial cells with the dependence of heparin or heparan sulfate proteoglycan (HSPG) in the extracellular matrix (ECM).

The participation of binding to heparin or HSPG leads to potential targets for antiangiogenic activity. It is well known that endostatin is an endogenous angiogenic protein that binds to heparin or HSPG and inhibits some functions of endothelial cells, resulting in a potent suppression of angiogenesis. Shimamura et al. [37] focused their attention on the characteristic positive-charge-rich surface of endostatin and 


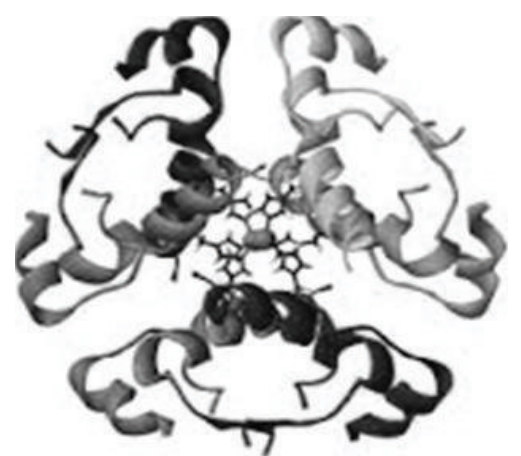

(a)

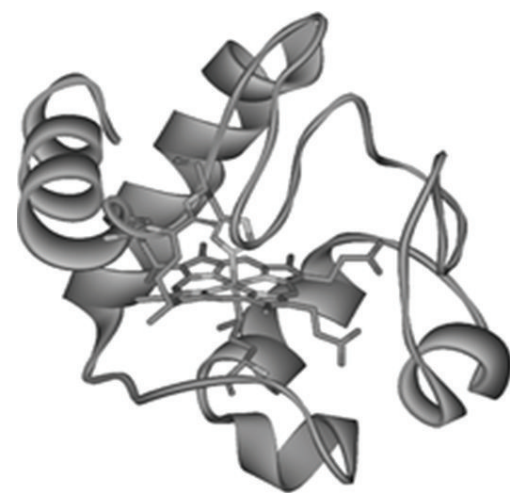

(b)

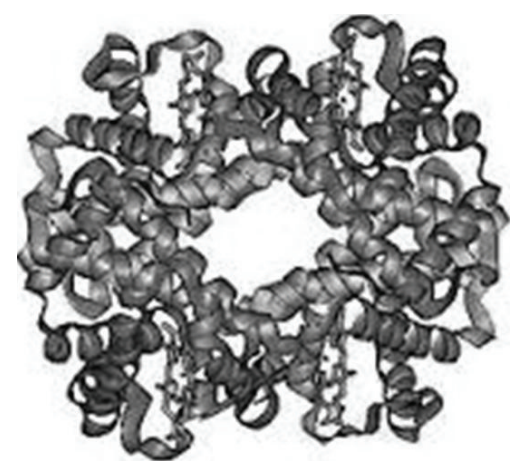

(c)

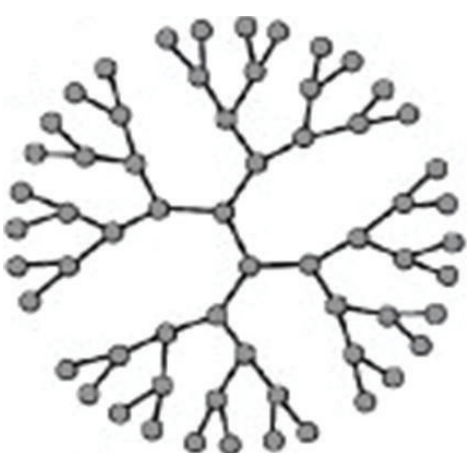

(d)

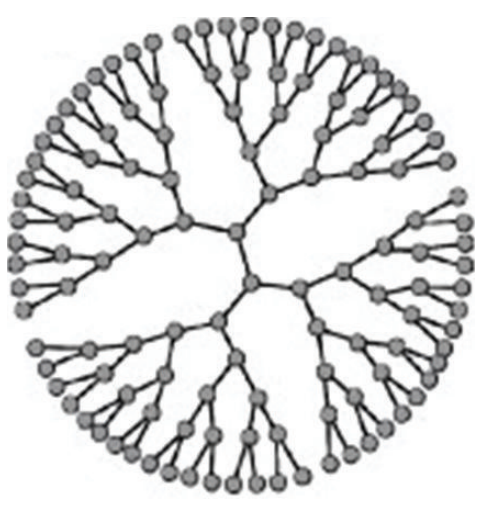

(e)

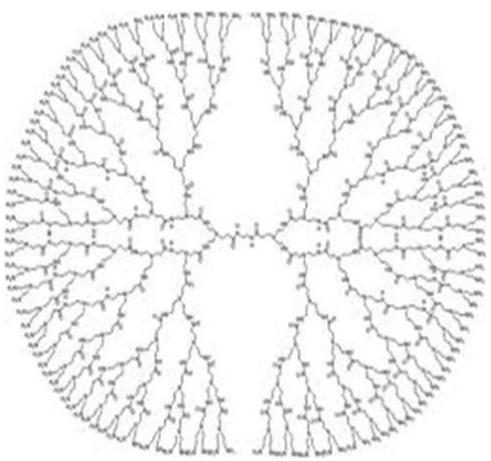

(f)

FIGURE 1: Size and shape comparison between protein and PAMAM dendrimers: (a) insulin, (b) cytochrome C, (c) hemoglobin, and PAMAM dendrimers generations (d) 3, (e) 4, and (f) 5 .

the interaction between its arginine residues (Arg) and either heparin or HSPG. This group designed novel arginine-rich dendrimers, TX-1943 (8 Arg residues), and TX-1944 (16 Arg residues), which mimic the surface structure of endostatin and evaluated their antiangiogenic ability, in vitro and in vivo. In vitro studies demonstrated that both dendrimers bound to heparin. Besides, this investigation showed that angiogenesis inhibition of b-FGF stimulated proliferation and tube formation of endothelial cells (Figure 3(a)). However, in vitro the antiangiogenic activity of TX-1944 was stronger than that of TX-1943 (Figure 3(b)). Moreover, both types of dendrimers exhibited potent antiangiogenic activity in the chicken embryo chorioallantoic membrane assay, in vivo. These data suggest that arginine dendrimer can be used to suppress or prevent the growth and metastasis of solid tumors.

2.2. Biomimetic Regeneration of Hydroxyapatite. Dental enamel is the hardest mineralized tissue in the human body $[38,39]$. This hard tissue comprises $96 \%$ inorganic materials and $4 \%$ organic materials and water by weight. The inorganic content is nanorod-like hydroxyapatite (HAP) crystals arranged into highly organized hierarchical microstructures. These special structures play an important role in 


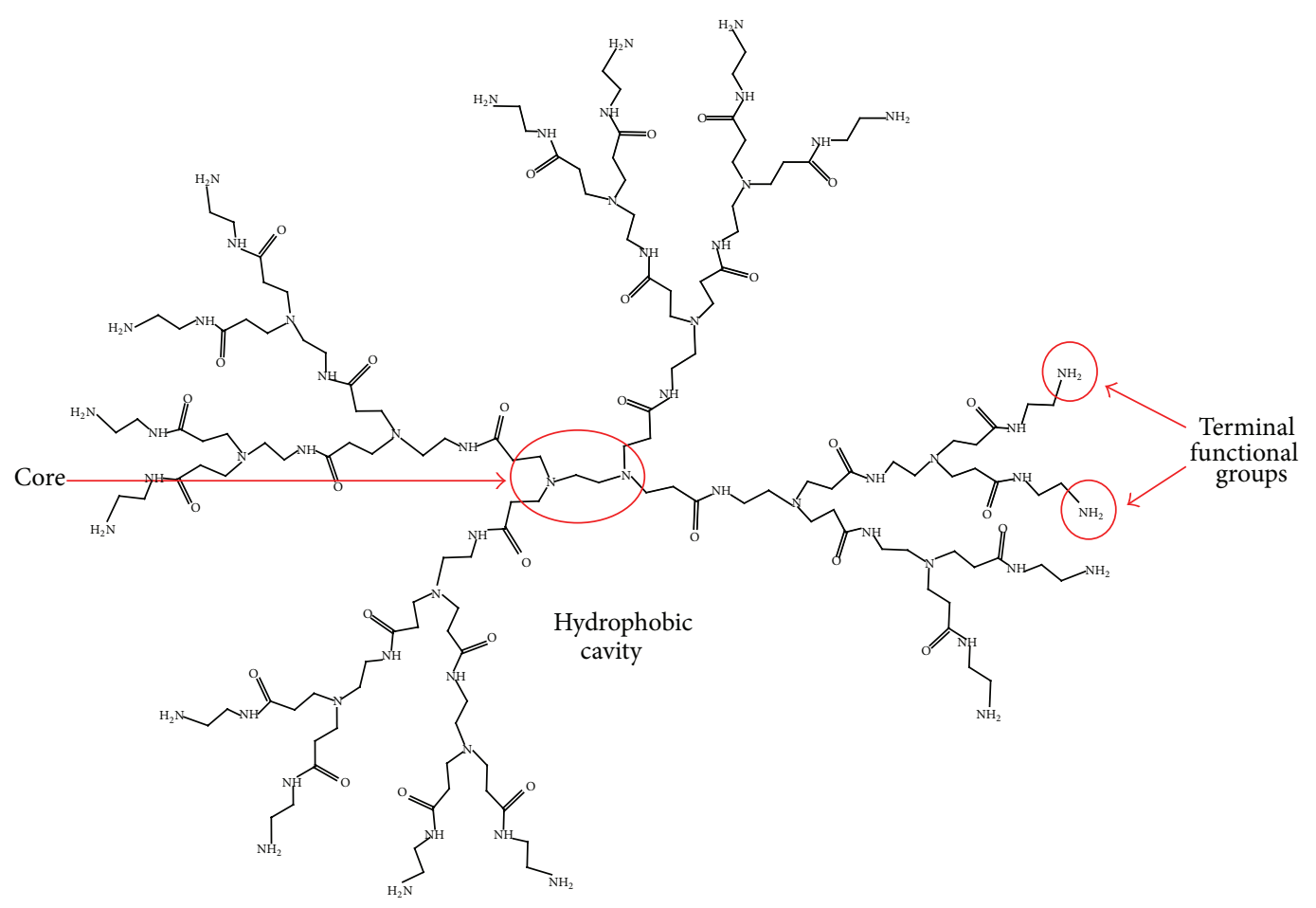

FIGURE 2: Representation of G2.0 PAMAM with 16 terminal amine groups.

determining the unique physicochemical properties of dental enamel. Recent studies have reported that extracellular matrix proteins, such as amelogenin, are essential for the control and modulation of these special structures during the biomineralization of enamel [40]. However, these proteins that induce and control the crystallization of apatite are almost completely degraded or removed during enamel maturation [41-47]. Therefore, unlike dentine and bone, mature enamel has no ability to reform highly organized crystals. Conventional treatments replace the defected enamel with substitute materials, such as resin and amalgam. These substitute materials are quite different from the normal enamel in chemical composition and crystal structure. Moreover, these materials require the sacrifice of healthy tooth tissue. Thus, the materials are not ideal for repairing defective enamel. Nowadays, biomimetic synthesis of enamel-like HAP has attracted much interest from research groups. Many methods have been used in vitro to form enamel-like crystals, including amelogenin, calcium phosphate solution, and nanohydroxyapatite. Some have used amelogenin to mimic the biomineralization process of enamel [48-55].

One study of biomimetic regeneration of hydroxyapatite was done by Chen et al. $[56,57]$. Their investigation set out to mimic protein-crystal interaction during biomineralization with the use of artificial proteins (dendrimers). They demonstrated that PAMAM dendrimers capped with carboxylic acid can be absorbed to enamel crystals. Recently, Wu et al. [58] synthesized carboxyl-terminated poly(amidoamine) (PAMAM-COOH), alendronate (ALN) conjugate (ALNPAMAM-COOH), in order to mimic the organic matrices induced biomineralization process in developing enamel and enhance the binding strength at the remineralization interface (Figure 4).

Overall, their results suggest that ALN-PAMAM-COOH is highly promising as a restorative biomaterial for in situ remineralization of human tooth enamel. Another example is the work of Chen et al. [59]; they investigated the effect of G3.0 PAMAM dendrimers with carboxylic acid (PAMAM$\mathrm{COOH}$ ) on crystal growth on etched enamel. Their study showed that PAMAM-COOH can function as an organic template on the demineralized enamel surface to induce the formation of HAP crystals with the same structure, orientation, and mineral phase of the intact enamel in relatively short time.

2.3. Collagen-Mimetic Dendrimers. Collagen is a fundamental constituent of extracellular matrixes on which tissues are built in vertebrates and comprises about one-third of proteins in animals [60]. It is a vital component of connective tissues such as bone, cartilage, skin, and tendon, and its high tensile strength is due to its triple helical structure. Collagen obtained from human cadavers and bovine sources induces disease transmission and allergic responses [61], so, it is necessary to develop synthetic and artificial material analogous to collagen. In this sense, Kinberger et al. [62] reported the synthesis of collagen mimetic dendrimers based on a trimesic acid (TMA) core structure and a tris-based scaffold. Gly-Pro-Nleu and Gly-Nleu-Pro sequences were used to synthesize collagen-mimetic dendrimers. Thermal denaturation monitored by optical rotation and circular dichroism measurement showed that dendrimers exhibited a triple-helical structure. Their results also indicated that 


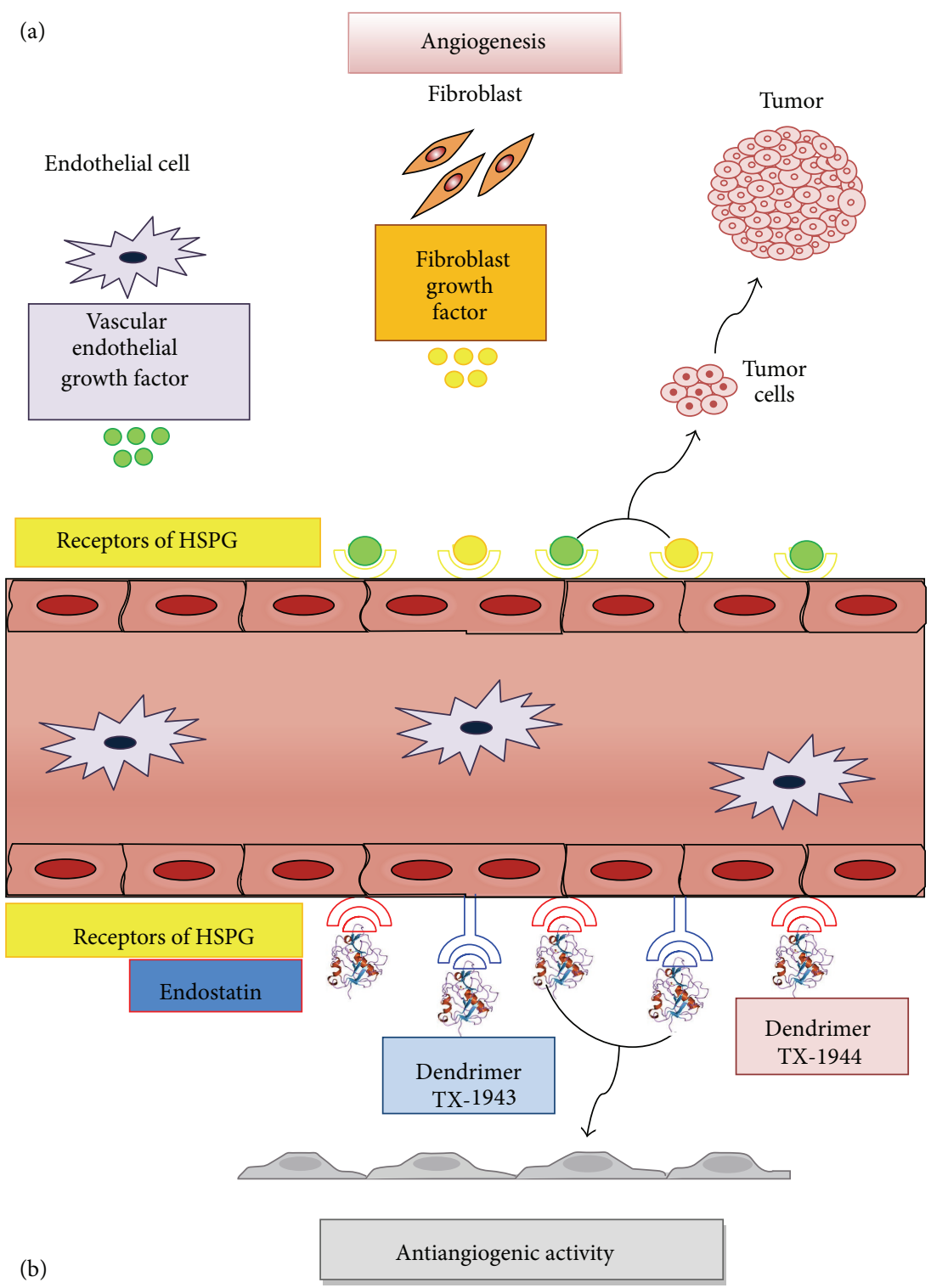

FIGURE 3: Schematic representation of (a) process of angiogenesis and (b) antiangiogenic activity of arginine-rich dendrimers,TX-1944 and TX-1943.
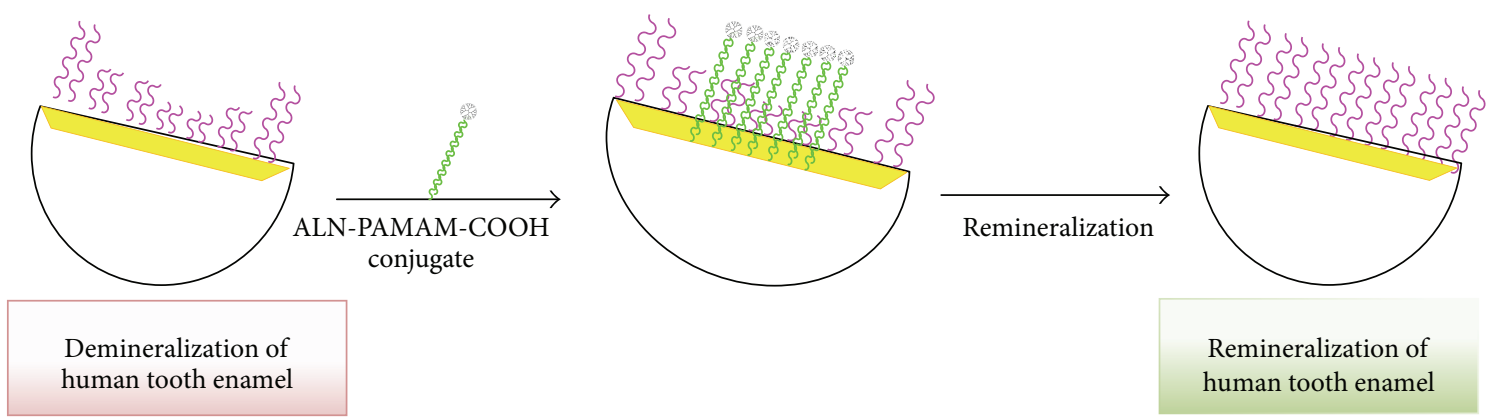

FIGURE 4: Schematic representation of the regeneration process of hydroxyapatite with alendronate (ALN) conjugate to carboxyl-terminated poly(amidoamine) (PAMAM). 


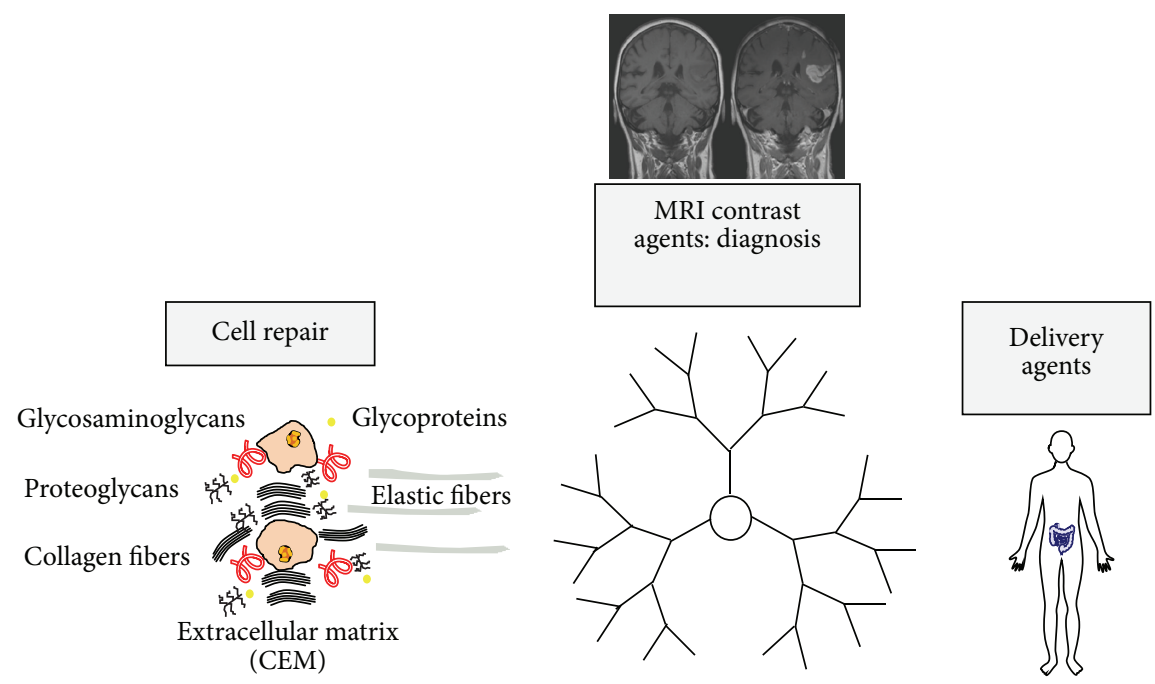

FIGURE 5: Schematic representation of the use of dendrimers in different medical applications: cell repair, diagnosis, and delivery agents.

collagen-mimetics synthesized from the Gly-Nleu-Pro sequence were thermally more stable triple-helical structures than the equivalent structures formed from the Gly-ProNleu sequence. The same group of researchers described another collagen-mimetic dendrimer composed of the Gly-Pro-Nleu sequence fabricated on a G1 PAMAM core [63]. The collagen-PAMAM conjugates were synthesized to prepare collagen mimetic dendrimers with increased functionality with respect to the TMA-based structures and to study the effect of different dendritic architecture on collagen mimetic melting transitions. They suggested that synthesis of PAMAM collagen-mimetic conjugates and their resultant complexation with metal cofactors such as $\mathrm{Cu}^{2+}$ and $\mathrm{Ni}^{2+}$ may have extraordinary biological properties.

\section{Dendrimers as Drug Delivery Agents}

Oral drug delivery is the most desirable route for polymeric drug carriers and has been used for the administration of many drugs. However, the oral bioavailability of polymeric drug carriers is often limited by their large size and molecular weight. Therefore, the variation in the mechanism and net permeability of polymeric drug carriers has been attributed to the difference in their structural features such as hydrodynamic volume, molecular weight, molecular geometry, and charge [64]. Dendrimers as drug delivery carriers are of great interest due to their highly controllable structure and size, and the terminal functional groups of dendrimers show higher chemical reactivity compared with other polymers [65]. The functional groups of dendrimers have been conjugated to various biologically active molecules. In this regard, PAMAM dendrimers have been extensively investigated for oral drug delivery [66-70], because they are a family of watersoluble polymers characterized by unique tree-like branching architecture and a compact spherical shape in solution [71]. Their potential as a drug carrier arises from the large number of arms and surface amine groups that can be utilized to immobilize drugs, enzymes, antibodies, or other bioactive agents (Figure 5) [72, 73].

Initial studies have showed that PAMAM dendrimers can permeate across epithelial barriers by a combination of transcellular and paracellular routes and can transiently open tight junctions. This enhances their transport via the paracellular pathway $[74,75]$ suggesting their potential as oral drug carriers $[76,77]$. However, limited data are available for a systematic correlation of the structure of these polymers with their transport across biological barriers, specifically the intestinal epithelia. In this sense, a general trend observed is that cationic PAMAM dendrimers are more toxic than their anionic counterparts, larger dendrimers are more toxic compared to smaller dendrimers of similar surface functionality, and masking cationic residues with noncharged groups improves tolerability of PAMAM dendrimers and their uptake by the epithelial cells [78].

Wiwattanapatapee et al. [79] investigated the effect of PAMAM dendrimer size, charge, and concentration on uptake and transport across the adult rat intestine in vitro using the everted rat intestinal sac system. They studied cationic PAMAM dendrimers (generations 3 and 4) and anionic PAMAM dendrimers (generations 2.5, 3.5, and 5.5). They showed that [80] I-labeled dendrimers suggested that transport across the intestinal membrane was charge dependent, and they demonstrated that cationic dendrimers tissue uptake was higher than serosal transport. Finally, 2.5G and 3.5G dendrimers were assumed to be transported through third-phase endocytosis. In contrast, 5.5G and cationic dendrimers were observed to be taken up by specific or nonspecific adsorptive endocytosis.

3.1. Dendrimers in Administration Drug. The application of dendrimers in pharmaceutical and medical chemistry is fast becoming one of the most attractive areas of dendrimer chemistry and the potential of dendrimers as drug 


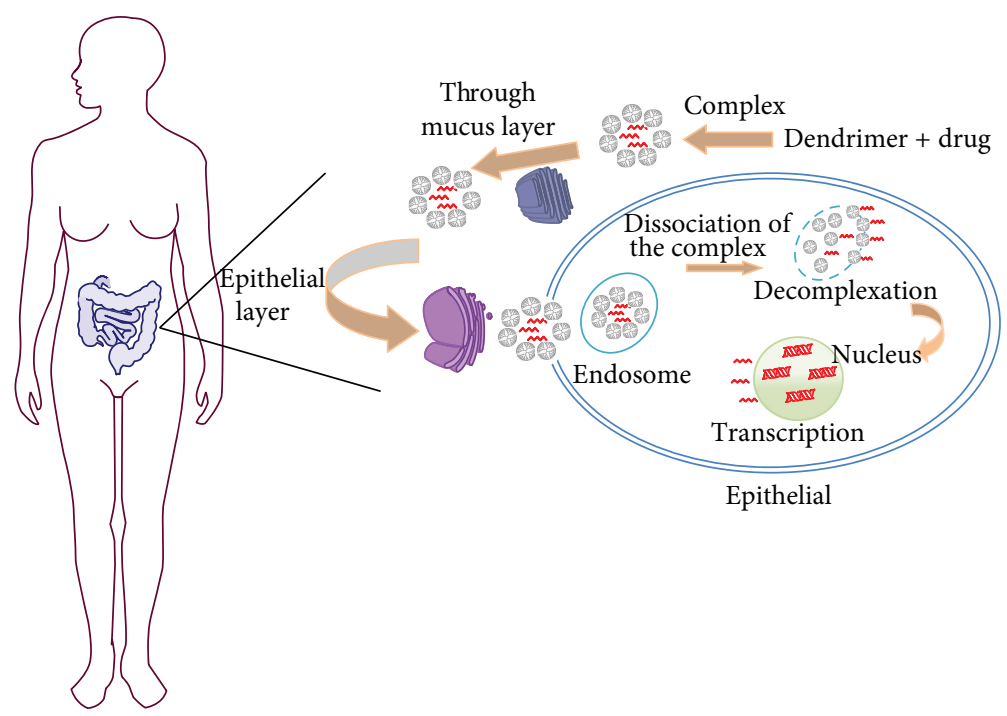

FIGURE 6: Schematic representation of transepithelial transport mechanism of dendrimer-drug complex.

administration agents has been explored for several researchers. For example, D’Emanuele et al. [81] synthesized prodrug by binding propranolol with $3 \mathrm{G}$ and lauroyl3G PAMAM dendrimer and determined the effect of these conjugates on transport of propranolol across the adenocarcinoma cell line CaCo-2. They observed the following: the apical (A) to basolateral (B) apparent permeability coefficient, Papp, of propranolol was increased and its $\mathrm{B} \rightarrow \mathrm{A}$ Papp decreased following conjugation to G3 dendrimers. Conjugation of propranolol to lauroyl-G3 dendrimers further increased its $\mathrm{A} \rightarrow \mathrm{B}$ Papp. Furthermore, they show that the $\mathrm{A} \rightarrow \mathrm{B}$ Papp of propranolol conjugates was reduced in the presence of the endocytosis inhibitor colchicine, suggesting that the enhancement mechanism involves endocytosis-mediated transepithelial transport (Figure 6). The $\mathrm{A} \rightarrow \mathrm{B}$ Papp of conjugated propranolol was not altered in the presence of the P-gp inhibitor cyclosporine A suggesting that conjugation of drug to dendrimer allows the bypassing of the efflux transporter. The results suggest that dendrimer-drug prodrugs may be used to increase drug solubility and bypass drug efflux transporters, therefore increasing drug bioavailability.

Subsequently, $\mathrm{Na}$ et al. [82] studied the prolonged delivery of ketoprofen using PAMAM dendrimers. Ketoprofen or 2-(3-benzoylphenyl)-propionic acid is a nonsteroidal anti-inflammatory drug with well-known anti-inflammatory, antipyretic, and analgesic properties. However, this drug has low solubility in water and causes local or systemic disturbance in the gastrointestinal tract. Therefore, this group investigated the potential of polyamidoamine (PAMAM) dendrimers as drug carriers of ketoprofen by in vitro and in vivo studies. The in vitro release of ketoprofen from the drug-dendrimer complex is significantly slower compared to pure ketoprofen. Antinociceptive studies using the acetic acid-induced writhing model in mice showed a prolonged pharmacodynamic behavior for the ketoprofen-PAMAM dendrimer complex.
Afterwards, Cheng et al. [83] investigated the potential of PAMAM dendrimers as drug carriers of CPT through aqueous solubility studies. Camptothecin (CPT), a plant alkaloid isolated from Camptotheca acuminata is a potent anticancer agent against a wide spectrum of human cancers, including lung, prostate, breast, colon, stomach, bladder, ovarian, and melanoma cancers. However, CPT has an extremely low solubility in aqueous medium, which presents a major challenge during drug formulation in clinical trials. Results showed that the aqueous solubility of CPT was significantly increased by PAMAM dendrimers.

In the same context, Goldberg et al. [84] evaluated G3.5 PAMAM dendrimer-SN38 (7-ethyl-10-hydroxycampothecin) conjugates with ester-linked glycine and $\beta$-alanine spacers for their suitability in oral therapy of hepatic colorectal cancer metastases. This work showed several important advantages about the use of G3.5-SN38 conjugates. First, because the drug is covalently conjugated to the dendrimer rather than complexed, the conjugates are relatively stable in the gastric and intestinal environments, minimizing premature drug release upon oral administration. Other studies conducted of G3.5-SN38 conjugates on Caco-2 monolayers, model of intestinal epithelial barrier, did not showed low cell viability, while comparable concentrations of SN38 caused significant cytotoxicity. Furthermore G3.5-glycine-SN38 and G3.5- $\beta$ Alanine-SN38 showed half maximal inhibitory concentrations values (IC50) of 0.60 and $3.59 \mu \mathrm{M}$, respectively, in HT-29 cells treated for $48 \mathrm{~h}$, and these data indicate the efficacy of the drug delivery system in colorectal cancer cells with longer incubation time. In addition, these systems can be used at higher concentrations $(100 \mu \mathrm{M}$ versus $10 \mu \mathrm{M})$ due to the low intrinsic toxicity of G3.5 dendrimers, allowing for greater drug transport across the gastrointestinal barrier and a higher dose at the site of action. Finally, G3.5-Gly-SN38 conjugates release the drug in the presence of carboxylesterase allowing for the targeted treatment of colorectal hepatic metastasis. 


\section{Dendrimers as Carriers or Scaffolds for Diagnosis and Therapy}

Dendrimers have been used to carry a variety of small molecule pharmaceuticals. These molecules have a number of advantages for use as carriers or scaffolds for diagnosis and therapy. For example, the amphiphilic property and the interior cavities of dendrimers can be used to encapsulate hydrophobic or hydrophilic drugs depending on dendrimer components $[85,86]$. In addition, dendrimers are monomolecular polymer micelles and this property avoids the instability of drug formulations using traditional amphiphilic polymers. On the other hand, the generationsize linear correlation of dendrimers means that they can be selected for a suitable size for specific biomedical applications. For example, medium-sized dendrimers of around $5 \mathrm{~nm}$ are used for MRI contrast agents in the diagnosis of lymphatic systems [87]. The highly branched, multivalent nature of dendrimers makes them ideal candidates for tissue engineering applications, and they are used as cross-linking agents, modulators of surface charge and surface chemistry, and primary components in scaffolds that mimic natural extracellular matrices.

4.1. Dendrimers as Anticancer Drug Carriers. Initial studies of dendrimers as potential delivery systems focused on their use as unimolecular micelles and "dendritic boxes" for the noncovalent encapsulation of drug molecules. For example, in early studies, DNA was complexed with PAMAM dendrimers for gene delivery applications [88], and hydrophobic drugs and dye molecules were incorporated into various dendrimer cores [89-92]. An advantage of using dendritic unimolecular micelles rather than conventional polymeric micelles is that the micellar structure is maintained at all concentrations because the hydrophobic segments are covalently connected. However, this approach suffers from a general drawback in that it is difficult to control the release of molecules from the dendrimer core. In some cases, harsh conditions are required, whereas in others the encapsulated drug is not well retained and the molecules are released relatively rapidly [93, 94]. An alternative approach to the development of dendrimers as anticancer drug carriers is to exploit their well-defined multivalency for covalent attachment of drug molecules to the dendrimer periphery. The drug loading can be tuned by varying the generation number of the dendrimer, and release of the drug can be controlled by incorporating degradable linkages between the drug and dendrimer. For example, encapsulation of the well-known anticancer drug cisplatin within PAMAM dendrimers gave conjugates that exhibited slower release, higher accumulation in solid tumors, and lower toxicity compared to free cisplatin [95].

In this regard, Malik et al. [96] prepared anticancer prodrugs, complexed carboxylate-terminated PAMAM dendrimers with cisplatin. They observed that cisplatin molecules can be released from the dendrimer scaffold by hydrolysis. Moreover, the prodrugs showed sustained release behavior $(<1 \%$ after $80 \mathrm{~h})$, much greater maximum tolerated dose, bioavailability of cisplatin, and prolonged survival period of tumor-bearing mice. Similarly, Malik and
Duncan [97] showed that the dendritic polymer platinates may be administered intravenously, orally, parentally, subcutaneously, or topically to an animal with a malignant tumor in an amount which effectively inhibits the growth of the tumor. Also, dendritic polymer platinates exhibit high drug efficiency, high drug carrying capacity, good water solubility, good stability on storage, reduced toxicity, and improved antitumor activity in vivo. On the other hand, the work of Balogh et al. [98] showed the encapsulation of silver salts within PAMAM dendrimers produced conjugates that exhibited slow silver release rates and antimicrobial activity against Staphylococcus aureus, Pseudomonas aeruginosa, and Escherichia coli bacteria.

4.2. Dendrimers as MRI Contrast Agents. Magnetic resonance imaging (MRI) is an important tool in modern medicine, providing high-quality three-dimensional images without the use of harmful ionizing radiation. The signal intensity in MRI stems mainly from the relaxation rate of in vivo water protons and is enhanced by the administration of a contrast agent prior to the scan. Such agents include a paramagnetic metal ion that decreases the relaxation times of nearby water protons. Different groups of contrast agents are established for clinical application: gadolinium chelates, superparamagnetic iron oxide particles, and hepatobiliary contrast agents. However, the gadolinium chelates constitute the largest group of MRI contrast agents and are considered to be safe. The crucial properties of MRI contrast agents include good biocompatibility, low toxicity, and high relaxivity. Low molecular weight MRI contrast agents diffuse rapidly from blood vessels into the interstitial space and are excreted from the body very rapidly [99]. Paramagnetic metal chelates such as $\mathrm{Gd}(\mathrm{III})-\mathrm{N}, \mathrm{N}^{\prime}, \mathrm{N}^{\prime \prime}, \mathrm{N}^{\prime \prime \prime}$-tetracarboxymethyl1,4,7,10-tetraazacyclododecane (Gd(III)-DOTA), Gd(III)diethylenetriamine pentaacetic acid (Gd(III)-DTPA), and their derivatives are used as contrast agents for magnetic resonance imaging (MRI), because these metal chelates increase the relaxation rate of surrounding water protons [100]. However, the shortcomings of these low molecular weight contrast agents include short circulation times within the body and inefficient discrimination between diseased and normal tissues. Subsequently, macromolecular Gd(III) complexes have been developed by conjugating Gd(III) chelates to biomedical polymers, including poly(amino acids), polysaccharides, and proteins to improve image contrast enhancement. These macromolecular agents have demonstrated superior contrast enhancement for blood pool imaging and cancer imaging in animal models. Unfortunately, the clinical application of macromolecular agents in general is limited by their slow excretion rate which results in their accumulation within the body, that is, the liver. In addition, the long residence time of MRI agents enhances the risk of potential toxicity by Gd(III) ions released during the metabolism of these agents $[101,102]$.

On the other hand, Wiener et al. [103] developed a new class of magnetic resonance imaging contrast agents, Gd(III)DTPA-based PAMAM dendrimers, with large proton relaxation enhancements and high molecular relaxivities. These 6th generation PAMAM dendrimers possess 192 reactive 
terminal amines, which can be conjugated to the chelating ligand 2-(4-isothiocyanato-benzyl)-6-methyl-(DTPA) through a thiourea linkage. This dendrimer has a relaxivity a six times higher than that of free Gd(III)-DTPA complex. In vivo experiments on rabbits show excellent MRI images of blood vessels and long blood circulation times (>100 min) upon intravenous injection. In addition, Kobayashi et al. [104] synthesized small dendrimer-based MRI contrast agents and investigated the relationship between relaxivity and dendrimer generations using Gd(III)-DTPA based PAMAM dendrimers. The results of this study revealed that relaxivities increased as the dendrimer generation increased, but there was no significant increase in relaxivities beyond 7 th generation.

4.3. Dendrimers as Tissue Regenerators. The field of tissue engineering has progressed greatly over the past few decades $[105,106]$. The goal of this field is the regeneration of native tissue by supplementing the natural healing process of the body or the creation of entire organs for transplantation. The first step constructing tissue construct is the selection of an appropriate scaffold material. Scaffolds may be as simple as a two-dimensional surface upon which cells can grow, or sophisticated scaffolds may encapsulate one or more cell types in three dimensions [107]. Most scaffolds are prepared as porous structures that allow for the diffusion of nutrients to and waste product away from the cells. The goal of tissue engineering applications is for the encapsulated cells to regenerate native extracellular matrix (ECM) and eventually replace the scaffold altogether. Therefore, the scaffold must biodegrade at a rate that complements the biosynthesis of new ECM.

Polymeric scaffold compositions can be divided into two main categories: natural and synthetic. Natural scaffolds are constructed from proteins, carbohydrates, or glycoproteins. Collagen is the most commonly used protein for scaffold construction [108]. Fibrin is another protein used for scaffold construction due to its ability to assemble into mesh-like networks [109]. Hyaluronic acid [110] and chondroitin sulfate [111] are key structural components and have been used extensively as tissue engineering scaffolds. Carbohydrates such as alginate [112], dextran [113, 114], and chitosan [115] are also used as scaffold materials due to their ability to form hydrated networks. The synthetic linear polymers, such as poly(lactic acid) (PLA), poly(glycolic acid) (PGA), poly(caprolactone) (PCL), and poly(ethylene glycol) (PEG) have also been used extensively as scaffold materials $[116,117]$.

4.3.1. Dendrimers in Cell Repair. Intact extracellular matrices (ECMs) have demonstrated potential as biomaterials in various tissue engineering and clinical applications $[118,119]$. These ECM scaffolds provide a natural three-dimensional support to aid the initial mechanical requirements necessary to support damaged or excised tissue [120-122]. In addition, ECM provides vital biological cues for cellular recognition which is essential for initial cellular attachment, subsequent cellular differentiation, in-growth of vascular networks, and secretion of new ECM requisite for eventual scaffold remodeling and tissue regeneration. Dendrimer works as a linker to the scaffold and as a carrier of bioactive molecules. The dense functional groups terminated on surface of dendrimers can react with intrinsic functional groups in protein-based scaffolds to form covalent binding. Conveniently in this way, scaffold stability can also be tailored by controlling the extent of cross-linking, which has the benefit of extending their in vivo life [123]. Availability of multiple functional groups effectively amplifies the number of sites available for conjugation with exogenous bioactive molecules. For example, Chan et al. [124] used generation 1 polyamidoamine (G1 PAMAM) dendrimer as a model dendrimer and incorporated into cholecyst-derived extracellular matrix (CEM), a novel intact extracellular matrix derived from the perimuscular subserosal connective tissue of porcine cholecysts developed in their laboratory [125]. They observed the incorporation of varied feed concentrations of PAMAM dendrimer in CEM using the EDC/NHS cross-linking system resulted in covalent binding of PAMAM on CEM. Varied degrees of cross-linking, improved stability of CEM to enzymatic degradation, increased amine functional groups useful in tethering bioactive agents, maintenance of tensile strength but increased flexibility of scaffold, and preservation of the ability of DENCEM to support cells in vitro were observed.

On the other hand, Boduch-Lee et al. [126] showed the design and synthesis of star polycaprolactone-hydroxyapatite films for use as a biodegradable matrix for bone tissue engineering. They used a hybrid scaffold composed of poly(caprolactone) (PCL) chains conjugated to a poly(Llysine) dendritic core to fabricate an HA-composite for in vitro bone regeneration. The effect of these scaffolds was evaluated in the cell line MG-63. They observed that the dendrimer-PCL HA hybrid performed much better than linear PCL, suggesting that the dendritic architecture presents advantages over linear polymers for the purposes of in vitro bone cell growth and adhesion over 24 hours.

4.4. Dendrimers in Vaccine Development. Vaccination has proven to be a very cost-effective way of controlling infectious diseases caused by microbial pathogens and has been known in its modern form since the pioneering work in the late 18 th century when Jenner introduced vaccinia (cowpox virus) as the first reliable vaccine [80]. Subsequently, many other successful vaccines have been developed, empirically, on the basis of attenuated or killed microorganisms or their toxins. Nevertheless, efficient vaccines are still needed for HIV1, tuberculosis, malaria, and a range of respirator and intestinal infectious diseases. Vaccination has been a powerful tool for eradicating smallpox and decreasing formerly widespread diseases like polio, measles, and rinderpest. Even so, a wide range of infectious diseases are still abundantly present around the globe (malaria, tuberculosis, and bacterial and viral diarrhea being the most widespread). Such diseases are generally caused by complex pathogens where a more rational approach in vaccine design is needed [127].

Therefore there is a growing need for a new-generation of vaccines to target these infectious diseases. With an increased knowledge of the molecular actions of the immune system, there is now a unique possibility to exploit welldefined chemical methods to create such new vaccines with 
optimal qualities. Dendrimers have optimal characteristics to fill the need for efficient immunostimulating compounds (adjuvants) that can increase the efficiency of vaccines. Also dendrimers can provide molecularly defined multivalent scaffolds to produce highly defined conjugates with small molecule immunostimulators and/or antigens [128]. These molecules are ideal carriers of small antigens, making it possible to prepare multimeric antigenic conjugates with well-defined molecular properties for human uses and they do not induce adverse host responses, including immune and/or inflammatory reactions upon administration. The interest has focused on one specific class of dendrimers, namely, the peptide dendrons described in 2005 by Crespo et al. [129]. Historically, these structures were rooted in the peptide world rather than the dendrimer world, peptides being the subject of intense interest as antigens in the $1980 \mathrm{~s}$ due to the advances in peptide solid-phase synthesis that were occurring at that time [130] and due to the realization that high-affinity immune reactivity demanded the development of efficient methods for presenting peptides to the immune system. The basic structure described by Tam [131] is a dendron constructed solely from lysine, taking advantage of the two amino groups ( $\mathrm{R}$ and $\varepsilon$ ) that are present in each lysine molecule and act as branching points for logarithmic growth. A two-layer dendron thus has four free amino groups and a three-layer dendron has eight, equally divided between Rand $\varepsilon$-amino groups. Tam coined the name "major antigenic peptide" (MAP) for such a structure derived from molecules of interest, not only limited to peptides, but also any small molecule that could bind covalently to the terminal amino groups of the MAP "core" dendron.

\subsubsection{Dendrimers as Molecularly Defined Carriers/Presenters} of Small Antigens. The final goal of human immunodeficiency syndrome (AIDS) research is a vaccine, since any combination of drugs has not caused a complete curing of AIDS [132]. In this sense, Wang et al. [133] examined the vaccine function of the multiple antigen peptide (MAP) which was synthesized by coupling the V3 loop (third variable region of envelope glycoprotein gp120 of HIV) sequence to lysine dendrimer by Tam [134], Tam and Lu [135]. They observed that the MAP elicited relatively high and sustained levels of HIV-1-specific neutralizing antibodies in animals. In the same context, Baigude et al. [136] reported the synthesis of first glycopeptide dendrimer-type AIDS vaccine model consisting of a V3 loop peptide-succinyl-maltose-prolinepoly(lysine) dendrimer scaffold. To increase the antigenic efficiency of V3 loop or related peptides, they designed glycopeptide dendrimer type AIDS vaccine with modified V3 peptide sequences. This vaccine model is different from the previously reported dendrimer vaccine, because it contains a sugar moiety. By introducing sugar into the dendrimer, enhancement in water solubility and decreases in the cell toxicity and the antigenicity of dendrimer itself can be achieved [137].

On the other hand, infection with Streptococcus pyogenes, commonly known as group A Streptococcus (GAS). It is responsible for acute and postinfectious complications, including rheumatic fever and rheumatic heart disease
(RHD). RHD is a global health burden, and Australia's indigenous population has one of the highest incidences of RHD worldwide. A potential peptide (J14) vaccine candidate has been previously identified from the C-terminal region of the $\mathrm{M}$ protein. However, such peptide-based vaccine development is hampered by a lack of carriers and adjuvants suitable for humans use. Zaman et al. [138] developed a fully synthetic peptide subunit vaccine candidate based on polyacrylate dendritic polymer. Intranasal administration of this nanoparticulate construct without additional adjuvant induced J14-specific IgG, which was also capable of in vitro opsonization of GAS, highlighting the potential of selfadjuvanting polyacrylate nanoparticle-based construct as a peptide vaccine delivery platform that may afford promising opportunities for treating systemic GAS infection.

In this regard, Wang et al. [139] reported immunization studies with a multiple antigen peptide vaccine designed to rely on "universal" $\mathrm{T}$ epitopes from tetanus toxin to produce T-cell help for induction of protective antibodies against the repeat region of the PyCSP. They observed that, when delivered with a nonionic block copolymer adjuvant, the vaccine protected $78 \%$ to $100 \%$ of three inbred strains of mice and $100 \%$ of outbred mice against "universal" T epitopes from tetanus toxin to produce T-cell help for induction of protective antibodies against the repeat region of the PyCSP challenge. In this sense, the protection was associated with antibody titer, and passive transfer of purified IgG from immune mice protected naive recipients. Similar protection was achieved when the peptide was encapsulated in liposomes with lipid A and mixed with aluminum hydroxide. This research showed for the first time solid protection against $P$. yoelii by polyclonal antibodies against the CSP, and these data provide the rationale for assessment of a similarly constructed and formulated $P$. falciparum CSP multiple antigen peptide vaccine in humans. By far, most of the reported immunizations with MAP constructs have been performed with traditional adjuvants. Moreno et al. [140] tested aluminium hydroxide, Freund's adjuvant, and a saponin adjuvant (QS21) for their ability to induce antibodies together with a MAP structure containing Plasmodium falciparum T- and B-cell stimulatory peptides. They observed that the addition of a coadjuvant QS-21, a purified saponin, significantly increased the immunogenicity of the alum-adsorbed MAP in both mice and monkeys, providing a vaccine formulation suitable for phase I trials in human volunteers. Another example is the work of Ota et al. [141]; they showed that pRL1a multiple antigen peptide- (MAP-) sensitized dendritic cell (DC) and P815 cell lysis by pRLla-specific B-24 CTL was blocked by incubating target cells at $4^{\circ} \mathrm{C}$ during sensitization. This finding suggested that pRLla MAP was mostly internalized in DC and P815 cells and produced pRLla peptide epitopes for presentation with $\mathrm{H}-2 \mathrm{~L}(\mathrm{~d})$. Furthermore, they showed that sensitization with pRL1a MAP was inhibited by the addition of chloroquine, cycloheximide, and brefeldin A to the culture.

\section{Dendrimers in Modified Electrodes}

The area of electrochemical biosensors has significant development in the past few years, with the development of 


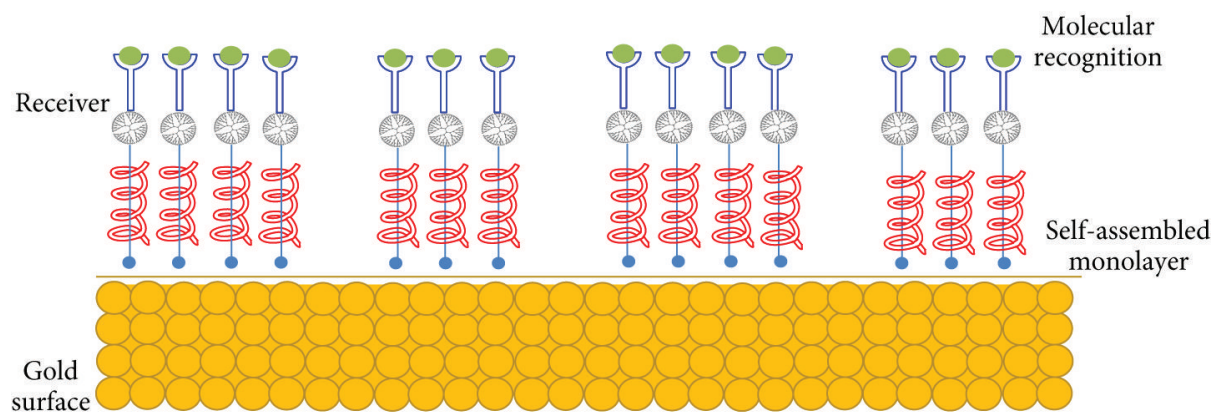

FIGURE 7: Schematic representation of an electrode modified with self-assembly monolayer over gold surface.

enzyme biosensors, immunosensors, and DNA sensors. Devices are being successfully used in clinical chemistry, food industry, and environmental fields. To achieve high specificity, high sensitivity, rapid response, and flexibility of use, it is clear that the research continues to focus on new assembly strategies. The use of layer-by-layer (LBL) assembly method for the design of electrochemical biosensors has attracted extensive attention. Recently, other strategies have been applied in the construction of LBL thin films through hydrogen-bonding interactions, charge-transfer interactions, biological interactions, and so forth. It would be possible to construct many different types of multilayer thin films through different LBL assembly strategies. The LBL technique has been found as a highly useful way for assembling a number of organic and inorganic substances with diverse nature, including proteins [142-144], DNA [145], viruses [146], dendrimers [147], and nanoparticles [148-150]. The organized multilayer architectures have attracted great interest because of their broad range of applications in the fields of biosensors, nonlinear optical devices, surface modification, and so forth.

On the other hand, in order to perform increasingly complicated and demanding tasks using chemically modified electrodes, complex molecular structures need to be constructed, with a high degree of control over the design and structure of the systems. This requirement has been tackled for polymer films on electrodes, where it has been demonstrated that, by constructing polymeric bilayers on electrodes, the electrode system may display unique properties [151-154]. Dendrimers are promising candidates for such functional coatings [155] due to their ability to self-organize into superstructures at the interfaces $[156,157]$. Their globular shape and multifunctional periphery make them well suited for the construction of multilayer nanocomposite materials. Besides, the multilayered configuration based on dendrimers offers advantages for several applications including catalysis, encapsulation and controlled release, chemical and biological sensors, and biomimetic materials. Because of the interior void structure of dendrimers [158], the resulting multilayer film puts up only minimal diffusion restriction for analytes and electron-transferring substances ensuring desired enzymatic and electrocatalytic reaction over the whole range of multilayers. Dendrimer modified electrodes have been used for the detection of halogenated organic acids [159] and for the construction of protein modified electrodes [160-162].
5.1. Dendrimers in the Design of an Electrochemical Detector or Sensors. The DNA microarray approach has become increasingly important in basic research into the genetics of disease and also in the more practical applications of medical diagnosis and treatment. Various methods have been used to detect sequence-selective DNA hybridization, including optical $[163,164]$, electrochemical $[165,166]$, and piezoelectric transduction techniques $[167,168]$. Of these techniques, the electrochemical method has attracted particular attention because of its high sensitivity, low cost, and compatibility with microfabrication technology. Studies in this direction have been developed by Kim et al. [169]; they developed a sandwich-type electrochemical DNA sensor using ferrocenyl-tethered poly(amidoamine) dendrimer (FCD) as electrocatalyst to enhance the electronic signals of DNA detection as well as a building block to immobilize capture probes. Fc-D was immobilized on a carboxylic acidterminated self-assembled monolayer (SAM) by covalent coupling of unreacted amine in Fc-D to the acid. They demonstrated that electrocatalysis enhanced the ability to discriminate between DNA sequences. Besides, the new combination of electrocatalysis using Fc-D and biochemical amplification with alkaline phosphatase (ALP) enabled the sequence-selective detection of various targets, including single-base mismatched oligonucleotide and also the quantification of target over a range of concentrations $(0.1 \mathrm{nM}$ to $10 \mu \mathrm{M})$. These results suggest that the introduction of the electroactive layer will allow highly sensitive amperometric measurements of ALP label in electrochemical enzyme immunoassay (EEIA) as well as DNA biosensors.

Similar idea was developed by Li et al. [170] who reported a sensitive electrochemical approach for sequence-specific DNA detection based on polyamidoamine (PAMAM) and signal amplification with nanoparticles (NPs, Figure 7). A gold electrode was modified with 3-mercaptopropionic acid and reacted with an amino-terminated polyamidoamine (PAMAM, G 4.0- $\mathrm{NH}_{2}$ ) to obtain a thin film. Single-stranded 3-biotin end-labeled oligonucleotide was immobilized onto the film to obtain a stable recognition layer through biotinavidin combination to detect complementary target, using signal amplification with Au NPs and $\left[\mathrm{Ru}\left(\mathrm{NH}_{3}\right)_{6}\right]^{3+}$ as redox electroactive indicators.

On the other hand, hydrogen peroxide is an essential mediator in food, pharmaceutical, clinical, industrial, and environmental analyses, so the determination of hydrogen 
peroxide is practically important. In this sense, Liu et al. [171] worked on the development of a $\mathrm{H}_{2} \mathrm{O}_{2}$ biosensor using self-assembly technique. The G4 PAMAM dendrimers were covalently linked to cystamine-modified Au electrode through glutaraldehyde cross-linking. With the help of the amino groups located on its surface, the nano-Au particles are adsorbed. Horseradish peroxidase (HRP) was attached to the electrode surface via nano-Au. When G4 PAMAM dendrimers were immobilized on the electrode, owing to their spherical structure, the surface area and the density of amino groups on the electrode increased, the amount of adsorbed nano-Au on the electrode also increased, and this would result in the increase of immobilized HRP. Thus, a higher sensitivity could be expected as compared with that of the conventional biosensors. The determination of $\mathrm{H}_{2} \mathrm{O}_{2}$ was performed with the aid of the electron mediator hydroquinone. In the presence of $\mathrm{HRP}, \mathrm{H}_{2} \mathrm{O}_{2}$ oxidized mediator $_{(\mathrm{Red})}$ into mediator ${ }_{(\mathrm{Ox})}$, the later was subsequently reduced at the electrode with an applied potential of $-200 \mathrm{mV}$ versus saturated calomel electrode (SCE). The resulting biosensor showed a linear response to $\mathrm{H}_{2} \mathrm{O}_{2}$ over a concentration range from $1 \times 10^{-5}$ to $2.5 \times 10^{-3} \mathrm{~mol} \mathrm{~L}^{-1}$ with a sensitivity of $0.53 \mathrm{~A} \mathrm{~L} \mathrm{~mol}^{-1} \mathrm{~cm}^{-2}$ and a detection limit of $2.0 \mu \mathrm{mol} \mathrm{L}^{-1}$ based on a signal-to-noise ratio of 3 . The apparent Michaelis-Menten constant $\left(K^{\mathrm{app}}\right)$ of the biosensor was evaluated to be $0.52 \mathrm{mmol} \mathrm{L}^{-1}$. The biosensor exhibited high sensitivity and good stability and reproducibility. Performance of the biosensor was evaluated with respect to possible interferences and the application to real sample analysis.

Tang et al. [172] reported that a novel amperometric biosensor based on self-assembling glutamate dehydrogenase $(\mathrm{GLDH})$ and poly(amidoamine) dendrimer-encapsulated platinum nanoparticles (Pt-PAMAM) onto multiwall carbon nanotubes (CNTs) has been developed for the determination of glutamate. The LbL film modified enzyme sensors showed a good reproducibility, stability, and high sensitivity, which can efficiently preserve the activity of enzyme molecules and prevent enzyme leaking. The results showed that it had series of attractive characteristics, such as a large determination range $(0.2-250 \mu \mathrm{M})$, a short response time (within $3 \mathrm{~s}$ ), a high sensitivity $\left(433 \mu \mathrm{A} / \mathrm{mM}^{-1} \mathrm{~cm}^{2}\right)$, and good stability $(85 \%$ remains after 4 weeks). The fabrication method of biosensor opens a new opportunity for the development of simple and reliable other enzymes. Moreover, the film is expected to have potential applications in the construction of screenprinted biosensor, in virtue of many advantages such as ease of fabrication and enhanced electrocatalysis.

Tang et al. [173] investigated an enhanced amperometric biosensor based on incorporating one kind of unique nanobiocomposite as dopant within an electropolymerized polypyrrole film. The nanobiocomposite was synthesized by self-assembling glutamate dehydrogenase (GLDH) and poly(amidoamine) dendrimer-encapsulated platinum nanoparticles (Pt-DENs) onto multiwall carbon nanotubes (CNTs) and the (GLDH/Pt-DENs) ${ }_{n} / \mathrm{CNTs} /$ Ppy hybrid film was obtained by electropolymerization of pyrrole onto glassy carbon electrodes. The results showed that the self-assembled
(GLDH/Pt-DENs) $)_{n} / \mathrm{CNTs}$ nanobiocomposites can be incorporated within polypyrrole film by electropolymerization method. The CNTs, Pt-DENs, and Ppy all played multiple functions, such as promotion electron transfer, improving the anti-interference ability, decreasing the overpotential, and keeping the enzyme activity, which greatly enhanced the performance of the resulting biosensor. The (GLDH/PtDENs) ${ }_{n} / \mathrm{CNT} / \mathrm{Ppy}$ hybrid film modified biosensor was used to detect glutamate as substrate with high sensitivity, low detection limit, fast response, and nearly free of interference. Thus, they demonstrated that the combination of special nanomaterials (CNTs and Pt nanoparticles) with conducting polypyrrole possesses a broad range of potential applications in all kinds of amperometric biosensor.

Bustos et al. [174] have designed different electrochemical detectors using modified electrodes; for example, they prepared composites of hydroxyl-terminated PAMAM dendrimers, generation 4.0 containing either $\mathrm{Ir}, \mathrm{Pt}$, or $\mathrm{Rh}$ nanoparticles (Figure 8). These composites were then immobilized on a glassy carbon electrode (GC) and incorporated as an amperometric detector for dopamine in a highperformance liquid chromatograph (HPLC). The analytical performance of the electrochemical detectors with a typical UV-Vis optical detector for dopamine revealed that the sensitivity of the GC electrode modified with dendrimer$\mathrm{Rh}$ composite is comparable to that of the spectroscopic detector, with a detection limit of $0.15 \mathrm{M}$, and is linear up to at least $1.0 \mathrm{mM}\left(R^{2}=0.998\right)$. Furthermore, they found that an electroanalytical approach suffers minimal matrix effects that arise in the analysis of dopamine in samples of urine.

In the same context, García et al. [175] prepared composites of hydroxyl-terminated PAMAM dendrimers generation 4.0, which containing Pt nanoparticles. These composites were synthesized at different reaction times using a microwave reactor. Next, they immobilized each composite electrochemically on a prefunctionalized glassy carbon (GC) electrode that was incorporated as a flow injection amperometric (FIA) detector, for the selective detection and quantification of dopamine (DA) in untreated urine samples. The analytical performance revealed that the DENsPt modified GC electrode with the composite synthesized for $30 \mathrm{~min}$ in the microwave reactor showed the best response for the detection of DA in samples of nontreated urine, since the detection and quantification limits are smaller (19 and 9 ppb, resp.) than those corresponding to the naked a GC electrode (846 and $423 \mathrm{ppb}$, resp.) using the FIA detector.

\section{Conclusion}

The characteristics of dendrimers, including high branching, well-defined globular structures, excellent structural uniformity, multivalency, variable chemical composition, and high biological compatibility, makes these compounds ideal carriers in biomedical applications such as drug delivery, imaging, and tissue engineering. Dendrimers are an important tool for drug discovery because of their ease of surface modification as well as their ability to interact with charged functional 


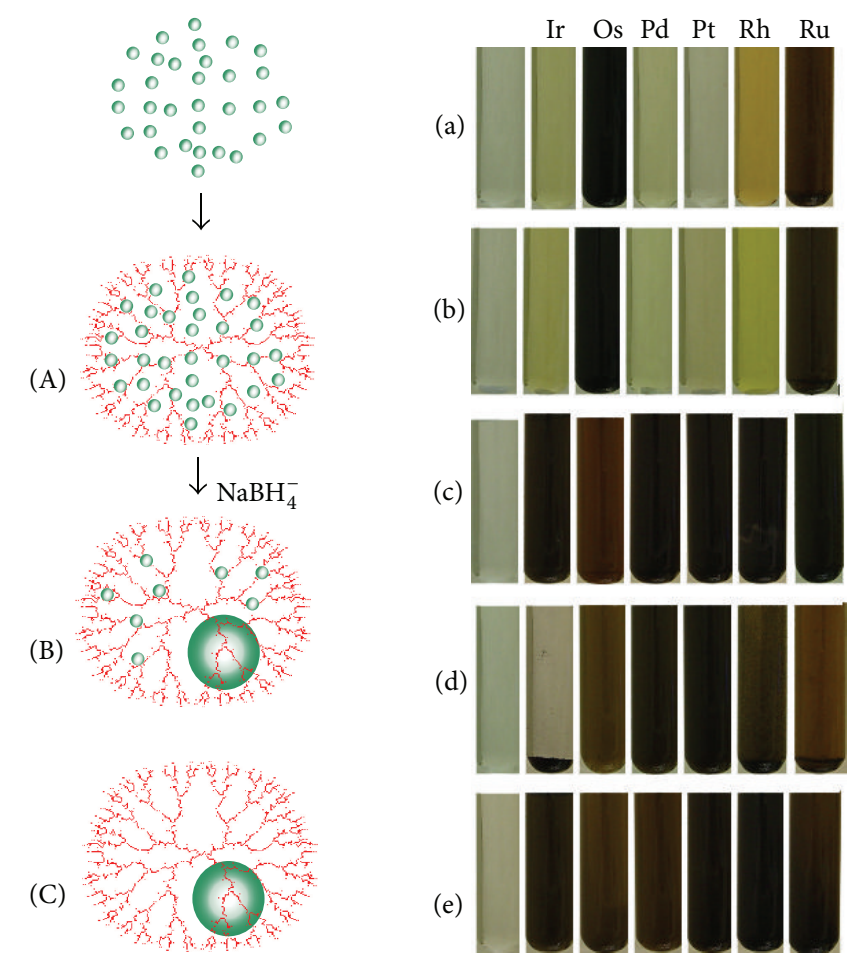

FIGURE 8: Schematic representation of the methodology used to prepare dendrimer aggregates (PG4.0), metal nanoparticles (DENs): (A) dendrimer complexes, ion, (B) ion chemical reduction, and (C) dialysis to purify the DENs formed. Images (a, b, c, and d) of the solutions prepared in each of the steps of the methodology to get nanoparticles: Ir, Os, Pd, Pt, Rh, and Ru.

groups. In addition, dendrimers are a new class of MRI contrast agents. However, for tissue engineering new scaffolds need to be designed with better chemical, mechanical, and biological features. On the other hand, dendrimers in the design of electrochemical detectors are promising research field for the development of new tools for supporting the diagnosis of diseases in a short time without a pretreatment of sample obtaining the lowest $\mathrm{DL}$ and QL in vivo detecting.

\section{Conflict of Interests}

The authors declare that there is no conflict of interests regarding the publication of this paper.

\section{Acknowledgments}

The authors would like to thank Consejo Nacional de Ciencia y Tecnología de los Estados Unidos Mexicanos (CONACyT), Fondo Mixto (FOMIX), Querétaro, and COLCIENCIAS, Code 110152128336, Contract RC4492011 for the funding of this research. B. Noriega-Luna is grateful to CONACyT for her postdoctorate scholarship. The authors also want to thank J. Dye, US Peace Corps volunteer at CIDETEQ, for his valuable comments and English revision of this paper.

\section{References}

[1] E. Buhleier, E. Wehner, and F. Vögtle, "Cascade-chain like and nonskid-chain-like synthesis of molecular cavity topologies," Synthesis, vol. 2, pp. 155-158, 1978.

[2] C. Wörner and R. Mülhaupt, "Polynitrile-and polyamine-functional poly(trimethylene imine) dendrimers," Angewandte Chemie International Edition, vol. 32, no. 9, pp. 1306-1308, 1993.

[3] E. M. M. de Brabander-van den Berg and E. W. Meijer, "Poly(propylene imine) dendrimers: large-scale synthesis by hetereogeneously catalyzed hydrogenations," Angewandte Chemie International Edition, vol. 32, no. 9, pp. 1308-1311, 1993.

[4] D. A. Tomalia, H. Baker, J. Dewald et al., "A new class of polymers: starburst-dendritic macromolecules," Polymer Journal, vol. 17, no. 1, pp. 117-132, 1984.

[5] G. R. Newkome, Z.-Q. Yao, G. R. Baker, and V. K. Gupta, "Micelles. Part 1. Cascade molecules: a new approach to micelles. A [27]-arborol," Journal of Organic Chemistry, vol. 50, no. 11, pp. 2003-2004, 1985.

[6] D. A. Tomalia, "Birth of a new macromolecular architecture: dendrimers as quantized building blocks for nanoscale synthetic polymer chemistry," Progress in Polymer Science, vol. 30, no. 3-4, pp. 294-324, 2005.

[7] C. J. Hawker and J. M. J. Fréchet, "Preparation of polymers with controlled molecular architecture. A new convergent approach to dendritic macromolecules," Journal of the American Chemical Society, vol. 112, no. 21, pp. 7638-7647, 1990. 
[8] R. Esfand and D. A. Tomalia, "Poly(amidoamine) (PAMAM) dendrimers: from biomimicry to drug delivery and biomedical applications," Drug Discovery Today, vol. 6, no. 8, pp. 427-436, 2001.

[9] P. Kolhe, J. Khandare, O. Pillai, S. Kannan, M. Lieh-Lai, and R. M. Kannan, "Preparation, cellular transport, and activity of polyamidoamine-based dendritic nanodevices with a high drug payload," Biomaterials, vol. 27, no. 4, pp. 660-669, 2006.

[10] J. J. Khandare, S. Jayant, A. Singh et al., "Dendrimer versus linear conjugate: influence of polymeric architecture on the delivery and anticancer effect of paclitaxel," Bioconjugate Chemistry, vol. 17, no. 6, pp. 1464-1472, 2006.

[11] S. Gurdag, J. Khandare, S. Stapels, L. H. Matherly, and R. M. Kannan, "Activity of dendrimer-methotrexate conjugates on methotrexate-sensitive and -resistant cell lines," Bioconjugate Chemistry, vol. 17, no. 2, pp. 275-283, 2006.

[12] A. K. Patri, J. F. Kukowska-Latallo, and J. R. Baker Jr., "Targeted drug delivery with dendrimers: comparison of the release kinetics of covalently conjugated drug and non-covalent drug inclusion complex," Advanced Drug Delivery Reviews, vol. 57, no. 15, pp. 2203-2214, 2005.

[13] A. D'Emanuele and D. Attwood, "Dendrimer-drug interactions," Advanced Drug Delivery Reviews, vol. 57, no. 15, pp. 21472162, 2005.

[14] U. Gupta, H. B. Agashe, A. Asthana, and N. K. Jain, "Dendrimers: novel polymeric nanoarchitectures for solubility enhancement," Biomacromolecules, vol. 7, no. 3, pp. 649-658, 2006.

[15] U. Boas and P. M. H. Heegaard, "Dendrimers in drug research," Chemical Society Reviews, vol. 33, no. 1, pp. 43-63, 2004.

[16] F. Aulenta, W. Hayes, and S. Rannard, "Dendrimers: a new class of nanoscopic containers and delivery devices," European Polymer Journal, vol. 39, no. 9, pp. 1741-1771, 2003.

[17] E. R. Gillies and J. M. J. Fréchet, "Dendrimers and dendritic polymers in drug delivery," Drug Discovery Today, vol. 10, no. 1, pp. 35-43, 2005.

[18] Y. Cheng, J. Wang, T. Rao, X. He, and T. Xu, "Pharmaceutical applications of dendrimers: promising nanocarriers for drug delivery," Frontiers in Bioscience, vol. 13, no. 4, pp. 1447-1471, 2008.

[19] M. Ma, Y. Cheng, Z. Xu et al., "Evaluation of polyamidoamine (PAMAM) dendrimers as drug carriers of anti-bacterial drugs using sulfamethoxazole (SMZ) as a model drug," European Journal of Medicinal Chemistry, vol. 42, no. 1, pp. 93-98, 2007.

[20] Y. Cheng, H. Qu, M. Ma et al., "Polyamidoamine (PAMAM) dendrimers as biocompatible carriers of quinolone antimicrobials: an in vitro study," European Journal of Medicinal Chemistry, vol. 42, no. 7, pp. 1032-1038, 2007.

[21] P. K. Tripathi, A. J. Khopade, S. Nagaich, S. Shrivastava, S. Jain, and N. K. Jain, "Dendrimer grafts for delivery of 5-flurouracil," Pharmazie, vol. 57, no. 4, pp. 261-264, 2002.

[22] R. Wiwattanapatapee, R. D. Jee, and R. Duncan, "PAMAM dendrimers as a potential oral drug delivery system: dendrimer complexes with piroxicam," Proceedings of the Controlled Release Society, no. 26, pp. 145-146, 1999.

[23] J. F. Kukowska-Latallo, K. A. Candido, Z. Cao et al., "Nanoparticle targeting of anticancer drug improves therapeutic response in animal model of human epithelial cancer," Cancer Research, vol. 65 , no. 12 , pp. 5317-5324, 2005.

[24] T. D. McCarthy, P. Karellas, S. A. Henderson et al., "Dendrimers as drugs: discovery and preclinical and clinical development of dendrimer-based microbicides for HIV and STI prevention," Molecular Pharmaceutics, vol. 2, no. 4, pp. 312-318, 2005.
[25] S.-G. Sampathkumar and K. J. Yarema, “Targeting cancer cells with dendrimers," Chemistry and Biology, vol. 12, no. 1, pp. 5-6, 2005.

[26] J. Solassol, C. Crozet, V. Perrier et al., "Cationic phosphoruscontaining dendrimers reduce prion replication both in cell culture and in mice infected with scrapie," Journal of General Virology, vol. 85, part 6, pp. 1791-1799, 2004.

[27] B. Klajnert, M. Cortijo-Arellano, J. Cladera, and M. Bryszewska, "Influence of dendrimer's structure on its activity against amyloid fibril formation," Biochemical and Biophysical Research Communications, vol. 345, no. 1, pp. 21-28, 2006.

[28] A. Chauhan, P. Diwan, N. Jain, and K. Raghavan, "Composition and complexes containing a macromolecular compound as potential anti-inflammatory agents," US Patent $20030180250 \mathrm{Al}$, 2003.

[29] M. Witvrouw, V. Fikkert, W. Pluymers et al., "Polyanionic (i.e., polysulfonate) dendrimers can inhibit the replication of human immunodeficiency virus by interfering with both virus adsorption and later steps (reverse transcriptase/integrase) in the virus replicative cycle," Molecular Pharmacology, vol. 58, no. 5, pp. 1100-1108, 2000.

[30] Y. Gong, B. Matthews, D. Cheung et al., "Evidence of dual sites of action of dendrimers: SPL-2999 inhibits both virus entry and late stages of herpes simplex virus replication," Antiviral Research, vol. 55, no. 2, pp. 319-329, 2002.

[31] C. Z. Chen, N. C. Beck-Tan, P. Dhurjati, T. K. van Dyk, R. A. LaRossa, and S. L. Cooper, "Quaternary ammonium functionalized poly(propylene imine) dendrimers as effective antimicrobials: structure-activity studies," Biomacromolecules, vol. 1, no. 3, pp. 473-480, 2000.

[32] M. Pospišil, L. Vannucci, A. Fišerova et al., "Glycodendrimeric ligands of c-type lectin receptors as therapeutic agents in experimental cancer," Advances in Experimental Medicine and Biology, vol. 495, pp. 343-347, 2001.

[33] L. Liu and R. Breslow, "Dendrimeric pyridoxamine enzyme mimics," Journal of the American Chemical Society, vol. 125, no. 40, pp. 12110-12111, 2003.

[34] L. Liu, M. Rozenman, and R. Breslow, "Hydrophobic effects on rates and substrate selectivities in polymeric transaminase mimics," Journal of the American Chemical Society, vol. 124, no. 43, pp. 12660-12661, 2002.

[35] S. Svenson and D. A. Tomalia, "Dendrimers in biomedical applications-reflections on the field," Advanced Drug Delivery Reviews, vol. 57, no. 15, pp. 2106-2129, 2005.

[36] S. Kasai, H. Nagasawa, M. Shimamura, Y. Uto, and H. Hori, "Design and synthesis of antiangiogenic/heparin-binding arginine dendrimer mimicking the surface of endostatin," Bioorganic and Medicinal Chemistry Letters, vol. 12, no. 6, pp. 951-954, 2002.

[37] M. Shimamura, S. Kasai, H. Nagasawa, H. Ashino, Y. Yamamoto, and Y. Uto, "Angiogenesis inhibition of arginine-rich dendrimers, TX-1943 and TX-1944, which mimic the surface structure of endostatin," Vascular Pharmacology, vol. 45, p. el19, 2006.

[38] L. C. Palmer, C. J. Newcomb, S. R. Kaltz, E. D. Spoerke, and S. I. Stupp, "Biomimetic systems for hydroxyapatite mineralization inspired by bone and enamel," Chemical Reviews, vol. 108, no. 11, pp. 4754-4783, 2008.

[39] J. P. Simmer and A. G. Fincham, "Molecular mechanisms of dental enamel formation," Critical Reviews in Oral Biology and Medicine, vol. 6, no. 2, pp. 84-108, 1995. 
[40] J. Moradian-Oldak, "Amelogenins: assembly, processing and control of crystal morphology," Matrix Biology, vol. 20, no. 56, pp. 293-305, 2001.

[41] L. Ye, T. Q. Le, L. Zhu et al., "Amelogenins in human developing and mature dental pulp," Journal of Dental Research, vol. 85, no. 9, pp. 814-818, 2006.

[42] C. Robinson, S. J. Brookes, J. Kirkham, W. A. Bonass, and R. C. Shore, "Crystal growth in dental enamel: the role of amelogenins and albumin," Advances in Dental Research, vol. 10, no. 2, pp. 173-180, 1996.

[43] L. Zhu, V. Uskoković, T. Le et al., "Altered self-assembly and apatite binding of amelogenin induced by $\mathrm{N}$-terminal proline mutation," Archives of Oral Biology, vol. 56, no. 4, pp. 331-336, 2011.

[44] C. Robinson, S. Connell, S. J. Brookes, J. Kirkham, R. C. Shore, and D. A. M. Smith, "Surface chemistry of enamel apatite during maturation in relation to $\mathrm{pH}$ : implications for protein removal and crystal growth," Archives of Oral Biology, vol. 50, no. 2, pp. 267-270, 2005.

[45] J. Moradian-Oldak, M. Iijima, N. Bouropoulos, and H. B. Wen, "Assembly of amelogenin proteolytic products and control of octacalcium phosphate crystal morphology," Connective Tissue Research, vol. 44, supplement 1, pp. 58-64, 2003.

[46] C. Du, G. Falini, S. Fermani, C. Abbott, and J. MoradianOldak, "Supramolecular assembly of amelogenin nanospheres into birefringent microribbons," Science, vol. 307, no. 5714, pp. 1450-1454, 2005.

[47] J. Moradian-Oldak, C. Du, and G. Falini, "On the formation of amelogenin microribbons," European Journal of Oral Sciences, vol. 114, supplement 1, pp. 289-296, 2006.

[48] J. E. Nör, “Tooth regeneration in operative dentistry," Operative Dentistry, vol. 31, no. 6, pp. 633-642, 2006.

[49] M. Iijima, C. Du, C. Abbott, Y. Doi, and J. Moradian-Oldak, "Control of apatite crystal growth by the co-operative effect of a recombinant porcine amelogenin and fluoride," European Journal of Oral Sciences, vol. 114, supplement 1, pp. 304-307, 2006.

[50] G. K. Hunter, H. A. Curtis, M. D. Grynpas, J. P. Simmer, and A. G. Fincham, "Effects of recombinant amelogenin on hydroxyapatite formation in vitro," Calcified Tissue International, vol. 65, no. 3, pp. 226-231, 1999.

[51] V. Uskoković, W. Li, and S. Habelitz, "Amelogenin as a promoter of nucleation and crystal growth of apatite," Journal of Crystal Growth, vol. 316, no. 1, pp. 106-117, 2011.

[52] Y. Fan, Z. Sun, and J. Moradian-Oldak, "Controlled remineralization of enamel in the presence of amelogenin and fluoride," Biomaterials, vol. 30, no. 4, pp. 478-483, 2009.

[53] M. Iijima, Y. Moriwaki, H. B. Wen, A. G. Fincham, and J. Moradian-Oldak, "Elongated growth of octacalcium phosphate crystals in recombinant amelogenin gels under controlled ionic flow," Journal of Dental Research, vol. 81, no. 1, pp. 69-73, 2002.

[54] N. Bouropoulos and J. Moradian-Oldak, "Induction of apatite by the cooperative effect of amelogenin and the $32-\mathrm{kDa}$ enamelin," Journal of Dental Research, vol. 83, no. 4, pp. 278-282, 2004.

[55] Y. Fan, J. R. Nelson, J. R. Alvarez, J. Hagan, A. Berrier, and $\mathrm{X} . \mathrm{Xu}$, "Amelogenin-assisted ex vivo remineralization of human enamel: effects of supersaturation degree and fluoride concentration," Acta Biomaterialia, vol. 7, no. 5, pp. 2293-2302, 2011.
[56] H. Chen, M. Banaszak Holl, B. G. Orr, I. Majoros, and B. H. Clarkson, "Interaction of dendrimers (Artificial Proteins) with biological hydroxyapatite crystals," Journal of Dental Research, vol. 82, no. 6, pp. 443-448, 2003.

[57] H. Chen, Y. Chen, B. G. Orr, M. M. B. Holl, I. Majoros, and B. H. Clarkson, "Nanoscale probing of the enamel nanorod surface using polyamidoamine dendrimers," Langmuir, vol. 20, no. 10, pp. 4168-4171, 2004.

[58] D. Wu, J. Yang, J. Li et al., "Hydroxyapatite-anchored dendrimer for in situ remineralization of human tooth enamel," Biomaterials, vol. 34, no. 21, pp. 5036-5047, 2013.

[59] L. Chen, K. Liang, J. Li, D. Wu, X. Zhou, and J. Li, "Regeneration of biomimetic hydroxyapatite on etched human enamel by anionic PAMAM template in vitro," Archives of Oral Biology, vol. 58, no. 8, pp. 975-980, 2013.

[60] C. L. Jenkins and R. T. Raines, "Insights on the conformational stability of collagen," Natural Product Reports, vol. 19, no. 1, pp. 49-59, 2002.

[61] L. R. Ellingsworth, F. DeLustro, J. E. Brenna, S. Sawamura, and J. McPherson, "The human immune response to reconstituted bovine collagen," Journal of Immunology, vol. 136, no. 3, pp. 877882, 1986.

[62] G. A. Kinberger, W. Cai, and M. Goodman, "Collagen mimetic dendrimers," Journal of the American Chemical Society, vol. 124, no. 51, pp. 15162-15163, 2002.

[63] G. A. Kinberger, J. P. Taulane, and M. Goodman, "The design, synthesis, and characterization of a PAMAM-based triple helical collagen mimetic dendrimer," Tetrahedron, vol. 62, no. 22, pp. 5280-5286, 2006.

[64] F. Tajarobi, M. El-Sayed, B. D. Rege, J. E. Polli, and H. Ghandehari, "Transport of poly amidoamine dendrimers across Madin-Darby canine kidney cells," International Journal of Pharmaceutics, vol. 215, no. 1-2, pp. 263-267, 2001.

[65] J. M. J. Fréchet, "Functional polymers and dendrimers: reactivity, molecular architecture, and interfacial energy," Science, vol. 263, no. 5154, pp. 1710-1715, 1994.

[66] M. El-Sayed, M. Ginski, C. Rhodes, and H. Ghandehari, "Transepithelial transport of poly(amidoamine) dendrimers across Caco-2 cell monolayers," Journal of Controlled Release, vol. 81, no. 3, pp. 355-365, 2002.

[67] K. M. Kitchens, R. B. Kolhatkar, P. W. Swaan, N. D. Eddington, and H. Ghandehari, "Transport of poly(amidoamine) dendrimers across Caco-2 cell monolayers: influence of size, charge and fluorescent labeling," Pharmaceutical Research, vol. 23, no. 12, pp. 2818-2826, 2006.

[68] R. B. Kolhatkar, P. Swaan, and H. Ghandehari, "Potential oral delivery of 7-ethyl-10-hydroxy-camptothecin (SN-38) using poly(amidoamine) dendrimers," Pharmaceutical Research, vol. 25, no. 7, pp. 1723-1729, 2008.

[69] M. Najlah, S. Freeman, D. Attwood, and A. D’Emanuele, “In vitro evaluation of dendrimer prodrugs for oral drug delivery," International Journal of Pharmaceutics, vol. 336, no. 1, pp. 183190, 2007.

[70] N. Vijayalakshmi, A. Ray, A. Malugin, and H. Ghandehari, "Carboxyl-terminated PAMAM-SN38 conjugates: synthesis, characterization, and in vitro evaluation," Bioconjugate Chemistry, vol. 21, no. 10, pp. 1804-1810, 2010.

[71] D. A. Tomalia, "Starburst/cascade dendrimers: fundamental building blocks for a new nanoscopic chemistry set," Advanced Materials, vol. 6, no. 7-8, pp. 529-539, 1994. 
[72] D. S. Wilbur, P. M. Pathare, D. K. Hamlin, K. R. Buhler, and R. L. Vessella, "Biotin reagents for antibody pretargeting. 3. Synthesis, radioiodination, and evaluation of biotinylated starburst dendrimers," Bioconjugate Chemistry, vol. 9, no. 6, pp. 813-825, 1998.

[73] N. A. Peppas, "Star polymers and dendrimers: prospects of their use in drug delivery and pharmaceutical applications," Controlled Release Society Newsletter, vol. 12, pp. 12-13, 1995.

[74] R. Jevprasesphant, J. Penny, D. Attwood, and A. D’Emanuele, "Transport of dendrimer nanocarriers through epithelial cells via the transcellular route," Journal of Controlled Release, vol. 97, no. 2, pp. 259-267, 2004.

[75] M. El-Sayed, C. A. Rhodes, M. Ginski, and H. Ghandehari, "Transport mechanism(s) of poly (amidoamine) dendrimers across Caco-2 cell monolayers," International Journal of Pharmaceutics, vol. 265, no. 1-2, pp. 151-157, 2003.

[76] A. T. Florence, T. Sakthivel, and I. Toth, "Oral uptake and translocation of a polylysine dendrimer with a lipid surface," Journal of Controlled Release, vol. 65, no. 1-2, pp. 253-259, 2000.

[77] R. Wiwattanapatapee, B. Carreno-Gomez, N. Malik, and R. Duncan, "PAMAM dendrimers as a potential oral drug delivery system: uptake by everted rat intestinal sacs in-vitro," Journal of Pharmacy and Pharmacology, vol. 50, no. 9, p. 99, 1998.

[78] N. Malik, R. Wiwattanapatapee, R. Klopsch et al., "Dendrimers: relationship between structure and biocompatibility in vitro, and preliminary studies on the biodistribution of ${ }^{125}$ I-labelled polyamidoamine dendrimers in vivo," Journal of Controlled Release, vol. 65, no. 1-2, pp. 133-148, 2000.

[79] R. Wiwattanapatapee, B. Carreno-Gomez, N. Malik, and R. Duncan, "Anionic PAMAM dendrimers rapidly cross adult rat intestine in vitro: a potential oral delivery system?" Pharmaceutical Research, vol. 17, no. 8, pp. 991-998, 2000.

[80] D. Mullin, "Prometheus in Gloucestershire: edward Jenner, 1749-1823," The Journal of Allergy and Clinical Immunology, vol. 112, no. 4, pp. 810-814, 2003.

[81] A. D'Emanuele, R. Jevprasesphant, J. Penny, and D. Attwood, "The use of a dendrimer-propranolol prodrug to bypass efflux transporters and enhance oral bioavailability," Journal of Controlled Release, vol. 95, no. 3, pp. 447-453, 2004.

[82] M. Na, C. Yiyun, X. Tongwen et al., "Dendrimers as potential drug carriers. Part II. Prolonged delivery of ketoprofen by in vitro and in vivo studies," European Journal of Medicinal Chemistry, vol. 41, no. 5, pp. 670-674, 2006.

[83] Y. Cheng, M. Li, and T. Xu, "Potential of poly(amidoamine) dendrimers as drug carriers of camptothecin based on encapsulation studies," European Journal of Medicinal Chemistry, vol. 43, no. 8, pp. 1791-1795, 2008.

[84] D. S. Goldberg, N. Vijayalakshmi, P. W. Swaan, and H. Ghandehari, "G3.5 PAMAM dendrimers enhance transepithelial transport of SN38 while minimizing gastrointestinal toxicity," Journal of Controlled Release, vol. 150, no. 3, pp. 318-325, 2011.

[85] J. Hu, Y. Su, H. Zhang, T. Xu, and Y. Cheng, "Design of interiorfunctionalized fully acetylated dendrimers for anticancer drug delivery," Biomaterials, vol. 32, no. 36, pp. 9950-9959, 2011.

[86] R. K. Tekade, P. V. Kumar, and N. K. Jain, "Dendrimers in oncology: an expanding horizon," Chemical Reviews, vol. 109, no. 1, pp. 49-87, 2009.

[87] H. Kobayashi and P. L. Choyke, "Methods for tumor treatment using dendrimer conjugates," US2006/0204443A1, 2006.

[88] J. Haensler and F. C. Szoka Jr., "Polyamidoamine cascade polymers mediate efficient transfection of cells in culture," Bioconjugate Chemistry, vol. 4, no. 5, pp. 372-379, 1993.
[89] J. F. G. A. Jansen, E. M. M. de Brabander-van den Berg, and E. W. Meijer, "Encapsulation of guest molecules into a dendritic box," Science, vol. 266, no. 5188, pp. 1226-1229, 1994.

[90] J. F. G. A. Jansen, E. W. Meijer, and E. M. M. de Brabandervan den Berg, "The dendritic box: shape-selective liberation of encapsulated guests," Journal of the American Chemical Society, vol. 117, no. 15, pp. 4417-4418, 1995.

[91] G. R. Newkome, C. N. Moorefield, G. R. Baker, M. J. Saunders, and S. H. Grossman, "Unimolecular micelles," Angewandte Chemie International Edition, vol. 30, no. 9, pp. 1178-1180, 1991.

[92] C. J. Hawker, K. L. Wooley, and J. M. J. Fréchet, "Unimolecular micelles and globular amphiphiles: dendritic macromolecules as novel recyclable solubilization agents," Journal of the Chemical Society, Perkin Transactions, vol. 1, no. 12, pp. 1287-1297, 1993.

[93] M. Liu, K. Kono, and J. M. J. Fréchet, "Water-soluble dendritic unimolecular micelles: their potential as drug delivery agents," Journal of Controlled Release, vol. 65, no. 1-2, pp. 121-131, 2000.

[94] C. Kojima, K. Kono, K. Maruyama, and T. Takagishi, "Synthesis of polyamidoamine dendrimers having poly(ethylene glycol) grafts and their ability to encapsulate anticancer drugs," Bioconjugate Chemistry, vol. 11, no. 6, pp. 910-917, 2000.

[95] N. Malik, E. G. Evagorou, and R. Duncan, "Dendrimer-platinate: a novel approach to cancer chemotherapy," Anti-Cancer Drugs, vol. 10, no. 8, pp. 767-776, 1999.

[96] N. Malik, R. Duncan, D. Tomalia, and R. Esfand, "An antineoplastic-dendritic polymer drug delivery system," EP1439859B1, 2007.

[97] N. Malik and R. Duncan, "Dendritic-platinate drug delivery system," US6585956B2, 2003.

[98] L. Balogh, D. R. Swanson, D. A. Tomalia, G. L. Hagnauer, and A. T. McManus, "Dendrimer-silver complexes and nanocomposites as antimicrobial agents," Nano Letters, vol. 1, no. 1, pp. $18-21,2001$.

[99] W.-D. Jang, K. M. Kamruzzaman Selim, C.-H. Lee, and I.K. Kang, "Bioinspired application of dendrimers: from biomimicry to biomedical applications," Progress in Polymer Science, vol. 34, no. 1, pp. 1-23, 2009.

[100] B. P. Hay, E. J. Werner, and K. N. Raymond, "Estimating the number of bound waters in $\mathrm{Gd}(\mathrm{III})$ complexes revisited. Improved methods for the prediction of q-values," Bioconjugate Chemistry, vol. 15, no. 6, pp. 1496-1502, 2004.

[101] P. Caravan, J. J. Ellison, T. J. McMurry, and R. B. Lauffer, "Gadolinium(III) chelates as MRI contrast agents: structure, dynamics, and applications," Chemical Reviews, vol. 99, no. 9, pp. 2293-2352, 1999.

[102] F. N. Franano, W. B. Edwards, M. J. Welch, M. W. Brechbiel, O. A. Gansow, and J. R. Duncan, "Biodistribution and metabolism of targeted and nontargeted protein- chelate-gadolinium complexes: evidence for gadolinium dissociation in vitro and in vivo," Magnetic Resonance Imaging, vol. 13, no. 2, pp. 201-214, 1995.

[103] E. C. Wiener, M. W. Brechbiel, H. Brothers et al., "Dendrimerbased metal chelates: a new class of magnetic resonance imaging contrast agents," Magnetic Resonance in Medicine, vol. 31, no. 1, pp. 1-8, 1994.

[104] H. Kobayashi, S. Kawamoto, S.-K. Jo, H. L. Bryant Jr., M. W. Brechbiel, and R. A. Star, "Macromolecular MRI contrast agents with small dendrimers: pharmacokinetic differences between sizes and cores," Bioconjugate Chemistry, vol. 14, no. 2, pp. 388394, 2003.

[105] R. Langer and J. P. Vacanti, “Tissue engineering," Science, vol. 260, no. 5110, pp. 920-926, 1993. 
[106] R. Langer and D. A. Tirrell, "Designing materials for biology and medicine," Nature, vol. 428, no. 6982, pp. 487-492, 2004.

[107] M. P. Lutolf and J. A. Hubbell, "Synthetic biomaterials as instructive extracellular microenvironments for morphogenesis in tissue engineering," Nature Biotechnology, vol. 23, no. 1, pp. 47-55, 2005.

[108] J. Glowacki and S. Mizuno, "Collagen scaffolds for tissue engineering," Biopolymers, vol. 89, no. 5, pp. 338-344, 2008.

[109] T. A. E. Ahmed, E. V. Dare, and M. Hincke, "Fibrin: a versatile scaffold for tissue engineering applications," Tissue Engineering B: Reviews, vol. 14, no. 2, pp. 199-215, 2008.

[110] D. L. Nettles, T. P. Vail, M. T. Morgan, M. W. Grinstaff, and L. A. Setton, "Photocrosslinkable hyaluronan as a scaffold for articular cartilage repair," Annals of Biomedical Engineering, vol. 32, no. 3, pp. 391-397, 2004

[111] Q. Li, C. G. Williams, D. D. N. Sun, J. Wang, K. Leong, and J. H. Elisseeff, "Photocrosslinkable polysaccharides based on chondroitin sulfate," Journal of Biomedical Materials Research A, vol. 68, no. 1, pp. 28-33, 2004.

[112] A. D. Augst, H. J. Kong, and D. J. Mooney, "Alginate hydrogels as biomaterials," Macromolecular Bioscience, vol. 6, no. 8, pp. 623633, 2006.

[113] M. P. Bajgai, S. Aryal, S. R. Bhattarai, K. C. R. Bahadur, K.W. Kim, and H. Y. Kim, "Poly( $\varepsilon$-caprolactone) grafted dextran biodegradable electrospun matrix: a novel scaffold for tissue engineering," Journal of Applied Polymer Science, vol. 108, no. 3, pp. 1447-1454, 2008.

[114] S. G. Lévesque and M. S. Shoichet, "Synthesis of enzymedegradable, peptide-cross-linked dextran hydrogels," Bioconjugate Chemistry, vol. 18, no. 3, pp. 874-885, 2007.

[115] T. Jiang, S. G. Kumbar, L. S. Nair, and C. T. Laurencin, "Biologically active chitosan systems for tissue engineering and regenerative medicine," Current Topics in Medicinal Chemistry, vol. 8, no. 4, pp. 354-364, 2008.

[116] J. L. Ifkovits and J. A. Burdick, "Review: photopolymerizable and degradable biomaterials for tissue engineering applications," Tissue Engineering, vol. 13, no. 10, pp. 2369-2385, 2007.

[117] C. P. Barnes, S. A. Sell, E. D. Boland, D. G. Simpson, and G. L. Bowlin, "Nanofiber technology: designing the next generation of tissue engineering scaffolds," Advanced Drug Delivery Reviews, vol. 59, no. 14, pp. 1413-1433, 2007.

[118] A. Atala, "Tissue engineering of artificial organs," Journal of Endourology, vol. 14, no. 1, pp. 49-57, 2000.

[119] L. E. Freed, F. Guilak, X. E. Guo et al., "Advanced tools for tissue engineering: scaffolds, bioreactors, and signaling," Tissue Engineering, vol. 12, no. 12, pp. 3285-3305, 2006.

[120] L. G. Griffith and G. Naughton, "Tissue engineering-current challenges and expanding opportunities," Science, vol. 295, no. 5557, pp. 1009-1014, 2002.

[121] D. A. Grande, A. S. Breitbart, J. Mason, C. Paulino, J. Laser, and R. E. Schwartz, "Cartilage tissue engineering: current limitations and solutions," Clinical Orthopaedics and Related Research, no. 367, pp. S176-S185, 1999.

[122] J. A. Hubbell, "Biomaterials in tissue engineering," Bio/Technology, vol. 13, no. 6, pp. 565-576, 1995.

[123] A. W. Bosman, H. M. Janssen, and E. W. Meijer, "About dendrimers: structure, physical properties, and applications," Chemical Reviews, vol. 99, no. 7, pp. 1665-1688, 1999.

[124] J. C. Y. Chan, K. Burugapalli, H. Naik, J. L. Kelly, and A. Pandit, "Amine functionalization of cholecyst-derived extracellular matrix with generation 1 PAMAM dendrimer," Biomacromolecules, vol. 9, no. 2, pp. 528-536, 2008.
[125] J. B. Wolinsky and M. W. Grinstaff, "Therapeutic and diagnostic applications of dendrimers for cancer treatment," Advanced Drug Delivery Reviews, vol. 60, no. 9, pp. 1037-1055, 2008.

[126] K. A. Boduch-Lee, T. Chapman, S. E. Petricca, K. G. Marra, and P. Kumta, "Design and synthesis of hydroxyapatite composites containing an mPEG-dendritic poly(L-lysine) star polycaprolactone," Macromolecules, vol. 37, no. 24, pp. 8959-8966, 2004.

[127] S. H. E. Kaufmann, "The contribution of immunology to the rational design of novel antibacterial vaccines," Nature Reviews Microbiology, vol. 5, no. 7, pp. 491-504, 2007.

[128] P. M. H. Heegaard, U. Boas, and N. S. Sorensen, "Dendrimers for vaccine and immunostimulatory uses. A review," Bioconjugate Chemistry, vol. 21, no. 3, pp. 405-418, 2010.

[129] L. Crespo, G. Sanclimens, M. Pons, E. Giralt, M. Royo, and F. Albericio, "Peptide and amide bond-containing dendrimers," Chemical Reviews, vol. 105, no. 5, pp. 1663-1681, 2005.

[130] G. B. Fields and R. L. Noble, "Solid phase peptide synthesis utilizing 9-fluorenylmethoxycarbonyl amino acids," International Journal of Peptide and Protein Research, vol. 35, no. 3, pp. 161214, 1990.

[131] J. P. Tam, “Multiple antigen peptide system,” US5229490A, 1993.

[132] D. H. Barouch, J. Kunstman, M. J. Kuroda et al., "Eventual AIDS vaccine failure in a rhesus monkey by viral escape from cytotoxic T lynphocytes," Nature, vol. 415, no. 6869, pp. 335-339, 2002.

[133] C. Y. Wang, D. J. Looney, A. M. Walfield et al., "Long-term hightiter neutralizing activity induced by octameric synthetic HIV-1 antigen," Science, vol. 254, no. 5029, pp. 285-288, 1991.

[134] J. P. Tam, "Synthetic peptide vaccine design: synthesis and properties of a high-density multiple antigenic peptide system," Proceedings of the National Academy of Sciences of the United States of America, vol. 85, no. 15, pp. 5409-5413, 1988.

[135] J. P. Tam and Y.-A. Lu, "Vaccine engineering: enhancement of immunogenicity of synthetic peptide vaccines related to hepatitis in chemically defined models consisting of T- and Bcell epitopes," Proceedings of the National Academy of Sciences of the United States of America, vol. 86, no. 23, pp. 9084-9088, 1989.

[136] H. Baigude, K. Katsuraya, K. Okuyama, and T. Uryu, "Synthesis of structurally-controlled AIDS vaccine model with glycopeptide dendrimer scaffolds," Macromolecular Chemistry and Physics, vol. 205, no. 5, pp. 684-691, 2004.

[137] A. D. Schlüter and J. P. Rabe, "Dendronized polymers: synthesis, characterization, assembly at interfaces, and manipulation," Angewandte Chemie International Edition, vol. 39, no. 5, pp. 864-883, 2000.

[138] M. Zaman, M. Skwarczynski, J. M. Malcolm et al., "Self-adjuvanting polyacrylic nanoparticulate delivery system for group A streptococcus (GAS) vaccine," Nanomedicine: Nanotechnology, Biology, and Medicine, vol. 7, no. 2, pp. 168-173, 2011.

[139] W. Wang, C. Charoenvit, C. Corradin et al., "Induction of protective polyclonal antibodies by immunization with a Plasmodium yoelii circumsporozoite protein multiple antigen peptide vaccine," Journal of Immunology, vol. 155, no. 3, p. 1637, 1995.

[140] C. A. Moreno, R. Rodriguez, G. A. Oliveira et al., "Preclinical evaluation of a synthetic Plasmodium falciparum MAP malaria vaccine in Aotus monkeys and mice," Vaccine, vol. 18, no. 1-2, pp. 89-99, 1999.

[141] S. Ota, T. Ono, A. Morita, A. Uenaka, M. Harada, and E. Nakayama, "Cellular processing of a multibranched lysine core with 
tumor antigen peptides and presentation of peptide epitopes recognized by cytotoxic $\mathrm{T}$ lymphocytes on antigen-presenting cells," Cancer Research, vol. 62, no. 5, pp. 1471-1476, 2002.

[142] Y. Lvov, K. Ariga, I. Ichinose, and T. Kunitake, "Assembly of multicomponent protein films by means of electrostatic layerby-layer adsorption," Journal of the American Chemical Society, vol. 117, no. 22, pp. 6117-6123, 1995.

[143] Y. M. Lvov, Z. Lu, J. B. Schenkman, X. Zu, and J. F. Rusling, "Direct electrochemistry of myoglobin and cytochrome P50 cam in alternate layer-by-layer films with DNA and other polyions," Journal of the American Chemical Society, vol. 120, no. 17, pp. 4073-4080, 1998.

[144] G. Decher, B. Lehr, K. Lowack, Y. Lvov, and J. Schmitt, "New nanocomposite films for biosensors: layer-by-layer adsorbed films of polyelectrolytes, proteins or DNA," Biosensors and Bioelectronics, vol. 9, no. 9-10, pp. 677-684, 1994.

[145] Y. Lvov, G. Decher, and G. Sukhorukov, "Assembly of thin films by means of successive deposition of alternate layers of DNA and poly(allylamine)," Macromolecules, vol. 26, no. 20, pp. 53965399, 1993.

[146] Y. Lvov, H. Haas, G. Decher et al., "Successive deposition of alternate layers of polyelectrolytes and a charged virus," Langmuir, vol. 10, no. 11, pp. 4232-4236, 1994.

[147] S. Watanabe and S. L. Regen, "Dendrimers as building blocks for multilayer construction," Journal of the American Chemical Society, vol. 116, no. 19, pp. 8855-8856, 1994.

[148] P. A. Fiorito, V. R. Gonçales, E. A. Ponzio, and S. I. Córdoba de Torresi, "Synthesis, characterization and immobilization of Prussian blue nanoparticles. A potential tool for biosensing devices," Chemical Communications, vol. 21, no. 3, pp. 366-368, 2005.

[149] F. Patolsky, T. Gabriel, and I. Willner, "Controlled electrocatalysis by microperoxidase-11 and Au-nanoparticle superstructures on conductive supports," Journal of Electroanalytical Chemistry, vol. 479, no. 2, pp. 69-73, 1999.

[150] Y. Lvov, B. Munge, O. Giraldo, I. Ichinose, S. L. Suib, and J. F. Rusling, "Films of manganese oxide nanoparticles with polycations or myoglobin from alternate-layer adsorption," Langmuir, vol. 16, no. 23, pp. 8850-8857, 2000.

[151] P. G. Pickup, W. Kutner, C. R. Leidner, and R. W. Murray, "Redox conduction in single and bilayer films of redox polymer," Journal of the American Chemical Society, vol. 106, no. 7, pp. 1991-1998, 1984.

[152] G. P. Kittlesen, H. S. White, and M. S. Wrighton, "Chemical derivatization of microelectrode arrays by oxidation of pyrrole and N-methylpyrrole: fabrication of molecule-based electronic devices," Journal of the American Chemical Society, vol. 106, no. 24, pp. 7389-7396, 1984.

[153] I. Rubinstein, "Electrostatic encapsulation using bi-polar polymer films on electrodes," Journal of Electroanalytical Chemistry, vol. 195, no. 2, pp. 431-434, 1985.

[154] I. Rubinstein and I. Rubinstein, "Bipolar polymeric arrangements on electrodes," Journal of Physical Chemistry, vol. 91, no. 1, pp. 235-241, 1987.

[155] D. A. Tomalia and J. M. J. Fréchet, "Discovery of dendrimers and dendritic polymers: a brief historical perspective," Journal of Polymer Science A: Polymer Chemistry, vol. 40, no. 16, pp. 27192728, 2002.

[156] V. V. Tsukruk, "Assembly of supramolecular polymers in ultrathin films," Progress in Polymer Science, vol. 22, no. 2, pp. 247311, 1997.
[157] V. V. Tsukruk and J. H. Wendorff, "Supramolecular polymers and assemblies: mesomorphism and beyond," Trends in Polymer Science, vol. 3, no. 3, pp. 82-89, 1995.

[158] D. A. Tomalia, A. M. Naylor, and W. A. Goddard III, "Starbust dendrimers: molecular-level control of size, shape, surface chemistry, topology, and flexibility from atoms to macroscopic matter," Angewandte Chemie International Edition, vol. 29, no. 2, pp. 138-175, 1990.

[159] J. Ledesma-García, J. Manríquez, S. Gutiérrez-Granados, and L. A. Godínez, "Dendrimer modified thiolated gold surfaces as sensor devices for halogenated alkyl-carboxylic acids in aqueous medium. A promising new type of surfaces for electroanalytical applications," Electroanalysis, vol. 15, no. 7, pp. 659666, 2003.

[160] L. Shen and N. Hu, "Heme protein films with polyamidoamine dendrimer: direct electrochemistry and electrocatalysis," Biochimica et Biophysica Acta-Bioenergetics, vol. 1608, no. 1, pp. 23-33, 2004.

[161] H. C. Yoon and H.-S. Kim, "Multilayered assembly of dendrimers with enzymes on gold: thickness- controlled biosensing interface," Analytical Chemistry, vol. 72, no. 5, pp. 922-926, 2000 .

[162] B. Alonso, P. García Armada, J. Losada, I. Cuadrado, B. González, and C. M. Casado, "Amperometric enzyme electrodes for aerobic and anaerobic glucose monitoring prepared by glucose oxidase immobilized in mixed ferrocene-cobaltocenium dendrimers," Biosensors and Bioelectronics, vol. 19, no. 12, pp. 16171625, 2004.

[163] P. A. E. Piunno, U. J. Krull, R. H. E. Hudson, M. J. Damha, and H. Cohen, "Fiber-optic DNA sensor for fluorometric nucleic acid determination," Analytical Chemistry, vol. 67, no. 15, pp. 26352643, 1995.

[164] R. Jenison, S. Yang, A. Haeberli, and B. Polisky, "Interferencebased detection of nucleic acid targets on optically coated silicon," Nature Biotechnology, vol. 19, no. 1, pp. 62-65, 2001.

[165] J. Wang, "Electrochemical nucleic acid biosensors," Analytica Chimica Acta, vol. 469, no. 1, pp. 63-71, 2002.

[166] E. Paleček, R. Kizek, L. Havran, S. Billova, and M. Fojta, "Electrochemical enzyme-linked immunoassay in a DNA hybridization sensor," Analytica Chimica Acta, vol. 469, no. 1, pp. 73-83, 2002.

[167] F. Caruso, E. Rodda, D. N. Furlong, K. Niikura, and Y. Okahata, "Quartz crystal microbalance study of DNA immobilization and hybridization for nucleic acid sensor development," Analytical Chemistry, vol. 69, no. 12, pp. 2043-2049, 1997.

[168] A. Bardea, A. Dagan, I. Ben-Dov et al., "Amplified microgravimetric quartz-crystal-microbalance analyses of oligonucleotide complexes: a route to a Tay-Sachs biosensor device," Chemical Communications, no. 7, pp. 839-840, 1998.

[169] E. Kim, K. Kim, H. Yang, Y. T. Kim, and J. Kwak, "Enzymeamplified electrochemical detection of DNA using electrocatalysis of ferrocenyl-tethered dendrimer," Analytical Chemistry, vol. 75, no. 21, pp. 5665-5672, 2003.

[170] G. Li, X. Li, J. Wan, and S. Zhang, "Dendrimers-based DNA biosensors for highly sensitive electrochemical detection of DNA hybridization using reporter probe DNA modified with Au nanoparticles," Biosensors and Bioelectronics, vol. 24, no. 11, pp. 3281-3287, 2009.

[171] Z.-M. Liu, Y. Yang, H. Wang, Y.-L. Liu, G.-L. Shen, and R.-Q. Yu, "A hydrogen peroxide biosensor based on nano-Au/PAMAM dendrimer/cystamine modified gold electrode," Sensors and Actuators B: Chemical, vol. 106, no. 1, pp. 394-400, 2005. 
[172] L. Tang, Y. Zhu, X. Yang, and C. Li, "An enhanced biosensor for glutamate based on self-assembled carbon nanotubes and dendrimer-encapsulated platinum nanobiocomposites-doped polypyrrole film," Analytica Chimica Acta, vol. 597, no. 1, pp. 145-150, 2007.

[173] L. Tang, Y. Zhu, L. Xu, X. Yang, and C. Li, "Amperometric glutamate biosensor based on self-assembling glutamate dehydrogenase and dendrimer-encapsulated platinum nanoparticles onto carbon nanotubes," Talanta, vol. 73, no. 3, pp. 438-443, 2007.

[174] E. B. Bustos, M. G. G. Jiménez, B. R. Díaz-Sánchez, E. Juaristi, T. W. Chapman, and L. A. Godínez, "Glassy carbon electrodes modified with composites of starburst-PAMAM dendrimers containing metal nanoparticles for amperometric detection of dopamine in urine," Talanta, vol. 72, no. 4, pp. 1586-1592, 2007.

[175] M. G. García, G. M. E. Armendáriz, A. Godínez Luis, J. Torres, S. Sepúlveda-Guzmán, and E. Bustos, "Detection of dopamine in non-treated urine samples using glassy carbon electrodes modified with PAMAM dendrimer-Pt composites," Electrochimica Acta, vol. 56, no. 22, pp. 7712-7717, 2011. 

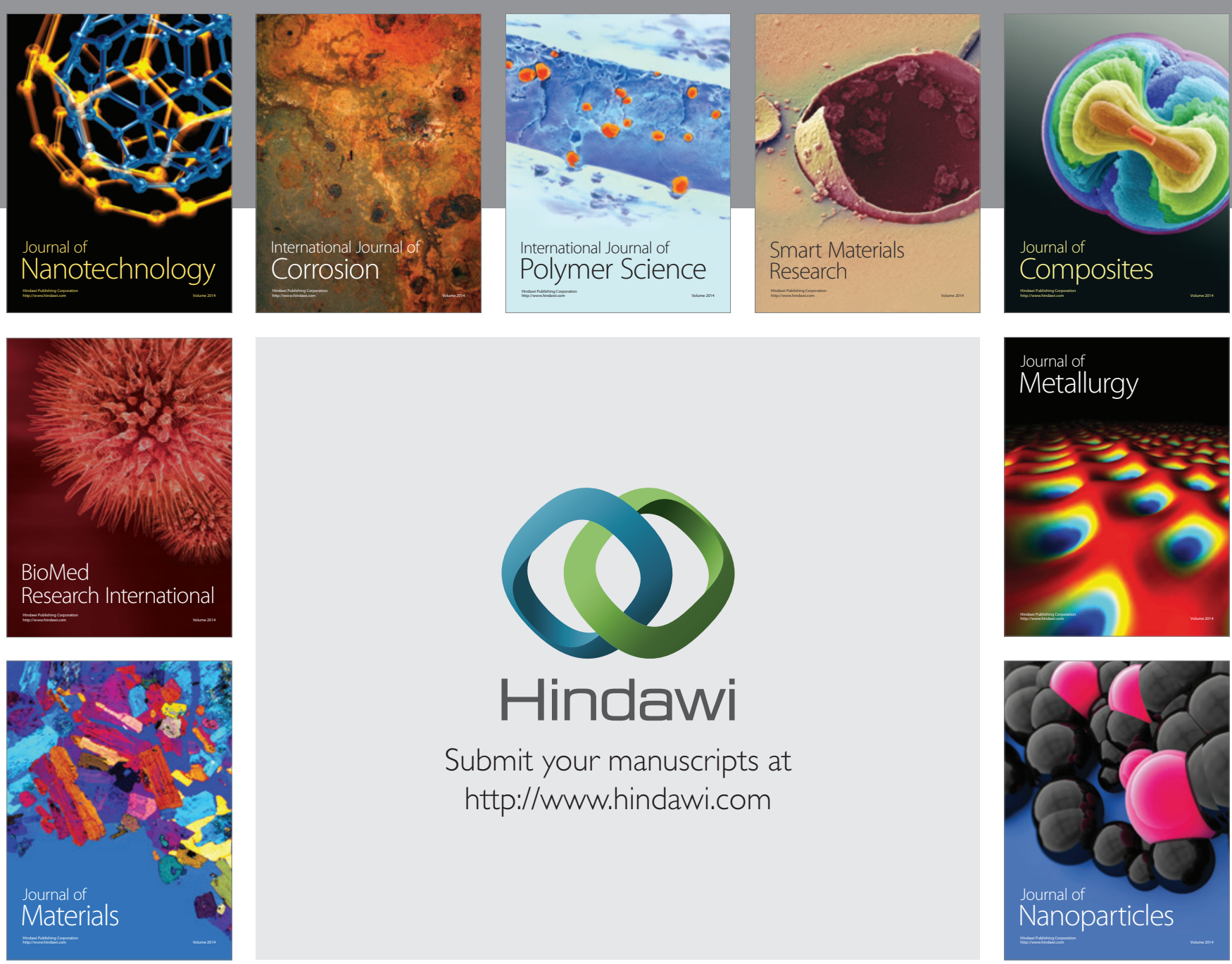

Submit your manuscripts at http://www.hindawi.com
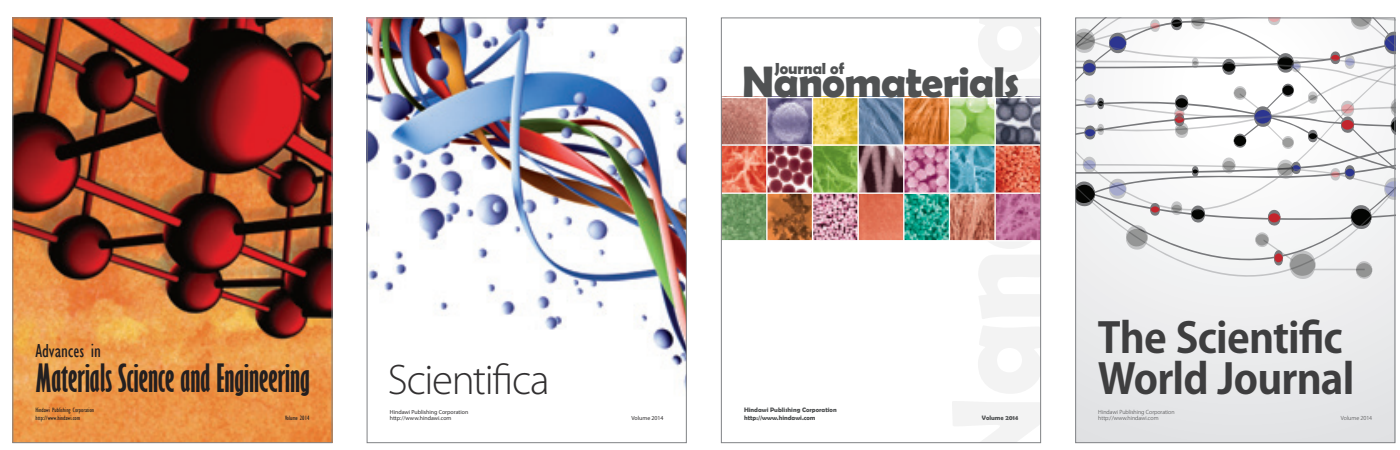

\section{The Scientific World Journal}
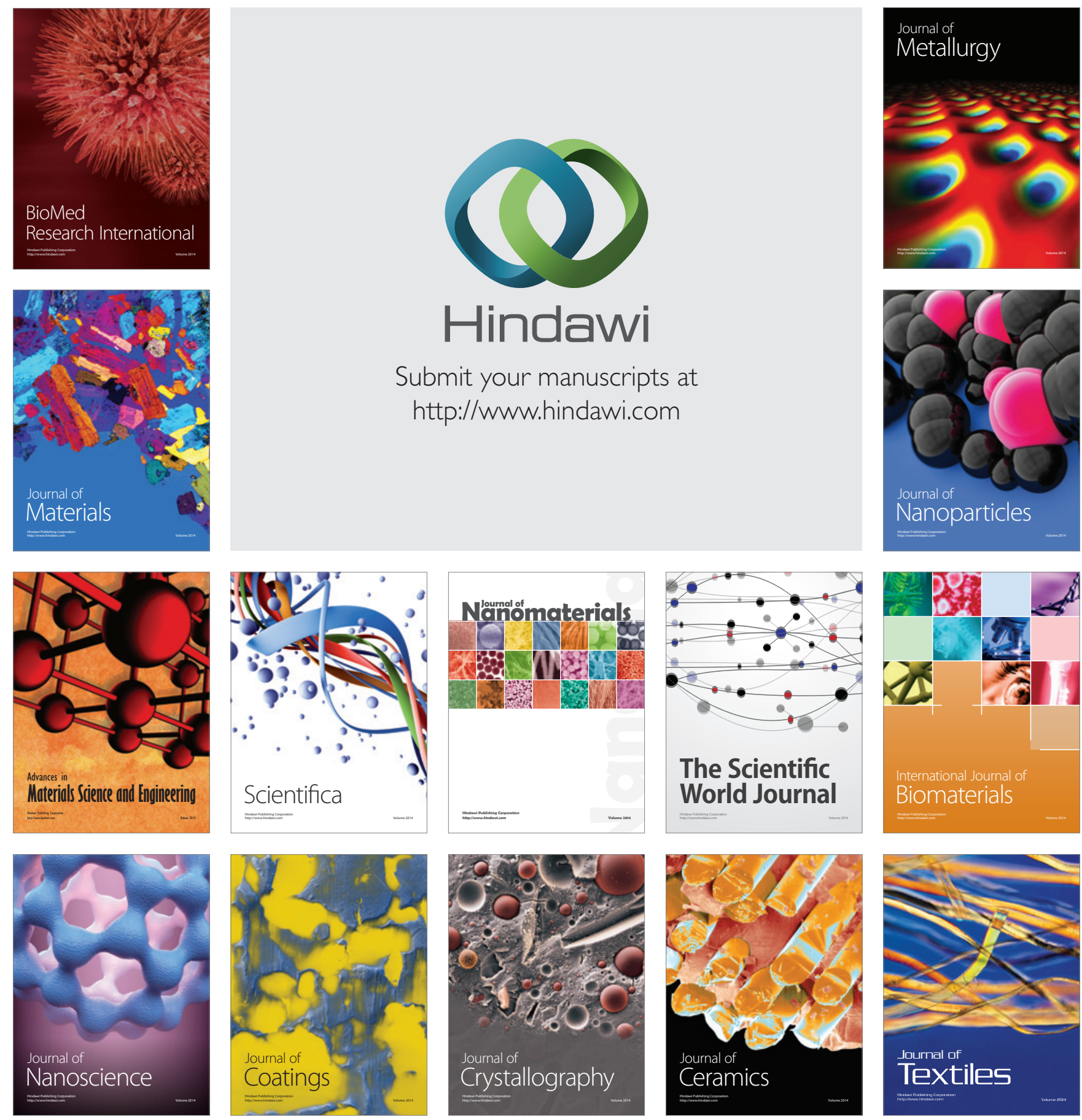